NBER WORKING PAPER SERIES

\title{
AREA DIFFERENCES IN UTILIZATION OF MEDICAL CARE AND MORTALITY AMONG U.S. ELDERLY
}

\author{
Victor R. Fuchs \\ Mark McClellan \\ Jonathan Skinner
}

Working Paper 8628

http://www.nber.org/papers/w8628

\author{
NATIONAL BUREAU OF ECONOMIC RESEARCH \\ 1050 Massachusetts Avenue \\ Cambridge, MA 02138 \\ December 2001
}

Paper presented at the NBER Conference on Aging at the Boulders, Carefree AZ, May 2001. For development of the variables used in this paper we are indebted to Jeffrey Geppert, Chris Kagay, Hoon Byun, and Sarah Rosen. We also thank Deborah Kerwin-Peck and Sarah Rosen for preparation of the tables and Dan Gottlieb for additional research assistance. Financial support was provided to Fuchs by the Robert Wood Johnson and Kaiser Family Foundations and to Mark McClellan and Jonathan Skinner by the National Institute on Aging. Helpful comments from David Cutler, Ed Glaeser, and especially Joseph Newhouse are gratefully acknowledged. The views expressed herein are those of the authors and not necessarily those of the National Bureau of Economic Research.

(C) 2001 by Victor R. Fuchs, Mark McClellan and Jonathan Skinner. All rights reserved. Short sections of text, not to exceed two paragraphs, may be quoted without explicit permission provided that full credit, including $\odot$ notice, is given to the source. 
Area Differences in Utilization of Medical Care and Mortality Among U.S. Elderly

Victor R. Fuchs, Mark McClellan and Jonathan Skinner

NBER Working Paper No. 8628

December 2001

JEL No. I11

\begin{abstract}
This paper examines 313 U.S. areas for differences in medical care utilization and mortality of whites ages 65-84 in 1990. The variables included in the analysis are education, real income, cigarette sales, obesity, air pollution, percent black, and dummy variables for seven regions and five population size categories from MSAs over 500,000 to not in MSA.

Utilization, especially inpatient care, is strongly positively related to mortality. Mortality is positively related to cigarette sales, obesity, air pollution and percent black. Utilization (especially outpatient) is significantly higher in MSAs with populations greater than 500,000. Mortality does not vary with population size, with or without controls. Florida is an outlier for both utilization (very high) and mortality (by far the lowest of any region). The puzzles of Floridian exceptionalism and the positive relation between white mortality and percent black are discussed but not resolved.
\end{abstract}

Victor R. Fuchs

NBER

30 Alta Road

Stanford, CA 94305
Mark McClellan

Department of Economics

Stanford University

Stanford, CA 94305

and NBER
Jonathan Skinner

Department of Economics

Dartmouth College

Hanover, NH 03755

and NBER 


\section{Introduction}

The two most important, most enduring questions in health economics are: (1) What are the determinants of expenditures? (2) What are the determinants of health? Extensive research over the last 35 years has produced a variety of answers to these questions, depending in large part on the specific context within which the questions are posed. One crucial distinction is between explaining changes over time and explaining cross-sectional differences at a given time. With regard to secular changes in the U.S. in recent decades, most health economists now believe that advances in medical technology provide the major explanation for both increases in expenditures and improvements in health. ${ }^{1}$ With regard to cross-sectional differences, the focus of this paper, there is less agreement. By exploiting a rich body of data from the Center for Medicare and Medicaid Services (formerly HCFA), the U.S. Census of Population, and other sources, we hope to narrow that disagreement, at least with respect to area differences in utilization of care and mortality of the elderly.

Our focus on the elderly is motivated in part by the fact that they account for a disproportionate share of national health care expenditures and an even greater share of government health care expenditures. Moreover, the elderly experience the bulk of the major health problems of the population. Approximately one-half of all deaths occur between ages 6584, and another one-fourth occur at ages 85 and above. These shares are based on the current age distribution of the U.S. population. For a stationary population experiencing current age-specific mortality rates, deaths at ages 65-84 would still account for almost one-half the total; the share at 85 and above would rise to one-third. The focus on the elderly is facilitated by the fact that the Medicare program generates a large, detailed body of data on utilization and mortality. 
One reason for focusing on area differences is that the large number of metropolitan and non-metropolitan areas in the U.S. provides a convenient framework for aggregating individual data in the search for variables that may be related to utilization and mortality. Moreover, many health policy analysts believe that an understanding of area differences may suggest opportunities to limit expenditures and/or improve health (e.g., Wennberg, Fisher, and Skinner, 2001).

This paper has two main sections: utilization and mortality. In most markets an interest in expenditures would require attention to prices as well as quantities, but given universal insurance coverage through Medicare and administrative price setting by HCFA, utilization is a natural subject for study. Mortality is only one of many possible measures of health, but there are several reasons to concentrate on it. First, mortality is by far the most objective measure. Secondly, it is, for most people, the most important health outcome. Thirdly, it is probably significantly correlated with morbidity since most deaths are preceded by illness.

In this paper we focus on "whites", ages 65-84, or more specifically, those not identified as African-American. We exclude blacks because at those ages both utilization and mortality of blacks are higher than for whites and the percentage black in an area is correlated with other variables of interest. Moreover, preliminary research by Donald Nichols suggests that the relationship between those other variables and utilization and mortality may be significantly different for blacks than for whites. We exclude anyone 85 and over because it is more difficult to obtain accurate measures for self-reported variables such as education and income. About one-half the population 85 and over suffer from some form of dementia and about one-fifth are in nursing homes where measurement of income is particularly problematic. Moreover, most nursing home utilization is not covered by Medicare, the source of our data on utilization. 
Briefly, we find wide variation in the utilization of health services across regions. It is not simply that some regions are higher along all dimensions of care, but that in some regions (Florida, for example) there is much more diagnostic testing, even while per capita inpatient services are comparable to the national average. In general, utilization is strongly positively associated with mortality across areas - in other words, areas with more sick elderly use more health care, other things equal. There remains, however, substantial variation in utilization after controlling for factors such as education, income, and mortality.

Cross-area variations in mortality rates among this elderly group are not as large as variations in utilization, but they are still substantial. The 10 percent of MSAs with the highest mortality (age-sex adjusted) have an average death rate 38 percent greater than the 10 percent of MSAs with the lowest mortality. The comparable differential between the high and low utilization areas is 49 percent.

Education, real income, cigarettes, obesity, air pollution, and the percent black account for more than half of the variation in mortality across areas, but there is still substantial differences across regions unexplained by these variables. Florida, in particular, has death rates significantly below the national average; the differential is particularly large for areas in the southern portion of the state. The final section of the paper explores two puzzles revealed by regression analyses: (1) Why Florida is so different from the rest of the country with respect to utilization and mortality; and (2) Why the presence of more blacks in an area should be associated with higher mortality among elderly whites. We considered several possible solutions to these puzzles, including differential migration patterns of the elderly, but ultimately we are left with conjectures rather than robust explanations. 


\section{Previous Studies}

\section{Spatial Variations in Health Care Utilization}

There is an extensive literature on geographic variations in health care spending and how it might be explained; we consider here a selective overview of these studies.

Researchers have documented variations across regions in health care utilization beginning with the studies by Glover in the 1930s, the work by Wennberg and associates in the 1970s and 1980s, and more recent studies by a wide variety of researchers. ${ }^{2}$ There is a general consensus that the variations are real and persistent over time. The Dartmouth Atlas of Health Care provides extensive documentation of the differences across regions for a variety of utilization measures (Wennberg and Cooper, 1999). In the Atlas studies, regions are defined based on Hospital Referral Regions (HRRs), each of which has at least one hospital with a tertiary cardiovascular or neurological surgical center. The geographical boundary of the HRR is based on the migration patterns of Medicare patients who use the hospitals inside the HRR, of which there are 306 in the U.S. Average 1995-96 fee-for-service Medicare per capita expenditures ranged from $\$ 3,506$ in Eugene, Oregon, $\$ 3,700$ in Minneapolis, \$7,783 in Miami, to $\$ 9,033$ in McAllen, Texas; these are all adjusted for age, sex, race, and regional price differences using a variant of the Part B price adjuster. Utilization rates of specific interventions that are not subject to the difficulties of price adjustment also show dramatic variations across regions. These differences are therefore best thought of as differences in quantities - hospital admissions, physician visits, and procedures - for the enrollees who live in each region, 
regardless of where they actually get their care.

Most of the controversy comes in how these variations can be interpreted. One clear possibility is factors related to demand; a sicker population, for example, should lead to greater demand for health care. Health status is clearly a critical determinant of health care utilization. Average annual spending for Medicare beneficiaries with "poor" self-assessed health is $\$ 8743$, but only $\$ 1656$ for those in excellent health (Wennberg and Cooper, 1996).

While regional differences in health status are clearly important determinants of health care spending (as we demonstrate below), they do not fully explain the two-fold differences in Medicare spending across regions. Even after accounting for differences across regions in underlying health measures such as stroke, heart attacks, hip fractures, cancer incidence, income, poverty rates, and behavioral factors such as the percentage of smokers and seatbelt users, one cannot explain more than 42 percent of the overall variation across regions in expenditures (Skinner and Fisher, 1997; Skinner, Fisher, and Wennberg, 2001). Longitudinal cohort studies also reveal differences in resource use across both hospitals and regions after controlling for patient health status and function (Chau, Fisher, and Skinner, 2001). ${ }^{3}$

A related "demand" based explanation is that patient preferences (owing to unmeasured illness or preferences for care holding illness constant) determine health care utilization, so that health care resources move to areas with the greatest demand as measured by initial physician visits or other indicators such as health (Escarce, 1992; Escarce, 1993; Folland and Stano, 1989; Green and Becker, 1994). In many of these studies, demand is inferred by the frequency of initial visits to the physician (as opposed to subsequent referrals, which are viewed as supply-driven). It remains an interesting, and largely untested question as to whether visits to physicians reflect 
demand (patient preferences) or supply (how often the physician schedules office visits).

Clearly, these demand-related factors can potentially explain some of the variation we observe, particularly in Florida where rates of utilization are higher than the rest of the country.

Another explanation is based on the supply of health care resources. The earliest incarnation of this link is "Roemer's Law," which states that if a hospital bed is built, it will be filled. In this view, the pre-existing resource capacity of the area, which arose out of historical accident, in turn determines the intensity of care in the region. In regions with greater supplies of hospital beds, inpatient expenditures are higher. A similar story holds for physician supply; larger populations of physicians per capita are associated with higher levels of per capita physician expenditures (Wennberg and Cooper, 1996, 1999).

However, correlation does not establish causation. One could expect more hospital beds to be built where there is greater demand, and one would expect physicians to move to regions where the demand of physician services is high. Furthermore, the correlations are not very strong. For example, using Dartmouth Atlas data, just one-quarter of the variation in Part B (physician) expenditures across the U.S. can be explained by physician supply. And while the supply of specialists in Miami is 45 percent higher than the supply in Minnesota, the number of visits by specialists to people in their last six months of life in Miami is more than 4 times larger. In other words, there appear to be significant nonlinearities in treatment patterns across regions that cannot be explained solely by differences in resource supply.

Another hypothesis, closely related to Wennberg's "practice style" theory is that some physicians show greater "enthusiasm" for specific procedures (Wennberg, Barnes, and Zubkoff, 1982; Chassin, 1993). A recent study surveyed both orthopedic surgeons and referring 
physicians with regard to their propensity to perform surgery (in the former case) and their perceptions of outcomes and propensity to refer (in the latter case), and found that these factors were highly significant in explaining overall knee replacement rates in the population, even after controlling for the underlying clinical conditions of the patients (Wright et al, 1999). The study did not, however, test patient preferences conditional on health needs.

A number of studies seeking to explain physician behavior have examined associations between specific physician psychosocial attributes or physician training or practice characteristics (years in practice, diversity of diagnoses managed, specialty) and measures of utilization (Allison, et al, 1998; Franks et al, 2000; Pearson et al., 1995; Selby et al, 1999). Although associations were generally weak, physicians with greater fear of malpractice, anxiety due to uncertainty, and less willingness to take risks were more likely to spend more per patient or more likely to refer. However, the magnitudes of these differences are not large enough to explain, by themselves, the wide regional variation in utilization.

As a statistical proposition, differences in physician enthusiasm by themselves are not enough to generate regional variations. Most regions include a large number of physicians, and if physicians are endowed with differing but randomly distributed levels of enthusiasm, they would average out over the large number of physicians in the area. (Of course, for some surgical procedures, one or two specialists could exert a strong influence on regional rates.) The interesting question therefore is why enthusiasm should be correlated across physicians within a given region.

Finally, factors that operate at the level of the hospital and market are also known to influence spending. Teaching status, membership in multi-hospital chains, degree of 
competition, and hospital ownership (e.g. for-profit ownership) have all been associated with differences in resource use (Gray and McNerney, 1986; Kessler and McClellan, 1999; Silverman, Skinner, and Fisher, 1999; Taylor, Whellan, and Sloan, 1999). The extent to which these factors contribute to regional differences in spending is not well understood.

Spatial Variations in Mortality

Spatial variations in mortality have not been studied as extensively as variations in utilization, and many studies have focused heavily on the influence of one or two variables such as air pollution or income inequality. The earliest investigations typically used states or a limited number of MSAs as the units of observation, thus suffering from the problem of few degrees of freedom. (Auster, Leveson, Sarachek, 1969, Morris Silver, 1972) Considerable effort has been devoted to studying the effects of income and education, and to sorting out the relative importance of these closely related variables. Both variables are usually found to be related to mortality, but their importance can vary greatly with age and cause of death. Income, for instance, is much more highly correlated with infant mortality than with deaths at other ages. Attempts to discover the impact of medical care have produced mixed results (FuchsKramer, 1972; Hadley 1988). More recently, Skinner, Fisher, and Wennberg (2001) used as an instrument physician visits in the last six months. This geographical variable was highly correlated with overall Medicare expenditures but uncorrelated with predicted survival based on regional measures of health. This study found "flat of the curve" effects of Medicare expenditures on survival, at least for the expenditures explained by physician visits in the last six months. Similar results were found using cohort data of heart attack patients controlling for detailed chart data using the Cooperative Cardiovascular Project data (Fisher et al, 2001). 
Several studies have found a positive association between air pollution and mortality. ${ }^{4}$ More recently, numerous investigators have focused on income inequality (rather than low income per se) as a major cause of higher mortality." In two comprehensive reviews of this literature Deaton (2001) and Deaton and Paxson (1999) critique the theoretical foundations of these studies and their empirical implementations. Deaton's attempts to find evidence of a relation between income inequality and mortality give no support to this popular hypothesis (Deaton and Paxson (2001) and Deaton and Lubotsky (2001)).

\section{Data and Estimation Strategy}

In this paper utilization is measured using a weighted index of quantities of services. We adopt this approach, instead of using Medicare expenditures, because it sidesteps the difficult problem of deflating Medicare expenditures across regions to "undo" differential payments made by Medicare for the same service in different areas. These differentials are introduced to offset differences in costs experienced by the providers of care and for other reasons. Deflated expenditures are also problematic to the extent that the residents of an area receive services in another area. In such cases, the price index of the area of residence is not the appropriate deflator. $^{6}$

We count the number of specific services received by the resident of an area, regardless of the area where the services were provided. Each detailed service is then weighted by the national reimbursement rate for that service; the sum of the weighted quantities divided by the number of Medicare enrollees is the total utilization for each area. Because this approach relies on billing codes for thousands of detailed services, systematic differences across areas in coding 
could introduce inaccuracies into this measure. Also, services not covered by Medicare are not included.

The year of the study is 1990 , with the utilization and mortality measures based on an average of 1989-91. Many of the other measures are obtained from the 1990 Census of Population. There are 224 metropolitan statistical areas (MSAs) with populations exceeding $100,000 .^{7}$ In addition, residents of MSAs with less than 100,000 are aggregated to one group within each state and residents outside MSAs are also aggregated to one group per state. The result is 313 areas. $^{8}$

In this paper the areas are aggregated into seven "regions" as follows:

\section{$\underline{\text { Region }} \quad \underline{\text { Census Divisions and States }}$}

1. North: New England, Middle Atlantic, and East North Central

2. Upper South: Delaware, Maryland, D.C., Virginia, and West Virginia

3. Deep South: North Carolina, South Carolina, Georgia, and East South Central

4. Florida: Florida

5. West/South: West South Central

6. Big Sky: West North Central, Montana, Idaho, Wyoming and Colorado

7. West: Pacific, Arizona, New Mexico, Utah and Nevada

This regional breakdown was developed by a geographer, Ge Lin, who found it to be more useful than the conventional census regions or divisions in studying disability among the elderly (Lin, 2000). We find this breakdown intuitively appealing, especially for the distinctions it makes among the southern states and among the mountain states and its treatment of Florida as a 
separate region.

We also aggregate areas according to their total population size in the following manner (1) Over 500,000, (2) 250,000 to 500,000, (3) 100,00 to 250,000, (4) Under 100,000 (aggregated to a single area within a state), and (5) Non MSAs (aggregated to a single area within each state). When regions and population size are used as dummy variables, the omitted categories are North and Over 500,000.

\section{Results}

Table 1 presents a list of variables included in this paper, giving the short name, definition, and source. For a fuller explanation of the derivation the utilization measures, see Appendix A. The utilization measure, mortality, percent high school dropout (LOED), and real income have all been adjusted for age and sex. Cigarette use and obesity are state measures; the same value is assigned to every area within each state. Particulate concentration (Pollution) is only available for MSAs $>100,000$.

Table 2 provides summary statistics for each variable. The means and standard deviations are calculated by weighting each area by its share of the population white ages $65-84$. Looking first at the means, we see that inpatient utilization accounts for about two-thirds of the total and outpatient utilization one-third. Admissions are approximately evenly divided between medical and surgical. Approximately one-half of total physician utilization is accounted for by treatment (procedures), about one-third by evaluation and management, and about one-sixth by diagnostic interventions.

The utilization measure shows considerably more variation across areas than does 
mortality. The relative variation in outpatient utilization is more than double that for inpatient utilization. As between medical admissions and surgical admissions, the former has twice the variation of the latter. Diagnosis has the most variation of the three types of physician services; all three have much greater variation than hospital admissions. This difference may be explained in part by more random variation in the measure of outpatient utilization, which has a smaller mean and is calculated from a smaller sample.

\section{$\underline{\text { Utilization Indexes By Region and Population Size }}$}

Tables 3 and 4 show indexes of utilization for areas grouped by region or population size for various types of utilization. All indexes are based on US=100. All are adjusted for age and sex, and areas are weighted by their population of whites $65-84$. The first column of Table 3 shows total utilization is much greater in Florida than in the rest of the country. Utilization is lowest in Big Sky. Across areas grouped by population size, total utilization is highest in the areas with over 500,000 population and, the $250,000-500,000$ population group is second highest. The other three categories all have below average utilization, with little difference among them.

Comparisons between indexes for inpatient (INUTIL) and outpatient (OUTUTIL) utilization (Table 3 columns 2 and 3) show many substantial differences, both for regions and population size. Most noteworthy is Florida, where the inpatient index is slightly below the national average, but outpatient utilization is approximately 55 percent above. In Big Sky the direction of difference is reversed; the inpatient index exceeds the outpatient index by more than 20 percentage points. Areas of large population size tend to show relatively more utilization of outpatient care; the reverse is true for MSAs $<100,000$ and the areas that are not MSAs. 
Substantial regional and population size differences in the indexes for medical admissions and surgical admissions can be seen in Table 4. In Florida, the index for surgical admissions is 15 percentage points higher than for medical admissions; the West region also has relatively more surgical admissions. In the three southern regions, medical admissions tend to be relatively higher than surgical admissions but the only big differential is in the Deep South.

The final utilization comparisons in Table 4 are among three types of physician services: evaluation and management, diagnosis, and treatment (surgical and non-surgical procedures). The differences for Florida are huge, with the index for diagnostic tests 63 percent above the U.S. average while evaluation and management is only 27 percent above. The procedures/treatment index is intermediate at 45 percent above the U.S. average. When only the areas above 100,000 are compared, the differentials are slightly smaller. In Big Sky the diagnostic test index is particularly low: 14 percentage points below the procedures/treatment index in the same region. Correlations Among The Different Measures of Utilization

Most measures of utilization are positively correlated, suggesting that the forces that influence variation in utilization across areas are stronger than the possibilities for substitution between various types of utilization. For example, the coefficient of correlation between inpatient and outpatient utilization is 0.27 , even though there are surely some opportunities for substitution between inpatient and outpatient care. Similarly, although some health problems can be treated either medically or surgically, the correlation between medical admissions and surgical admissions is 0.47 . The largest negative correlation, -0.13 , is between medical admissions and physicians' diagnostic services. (For a full set of correlation coefficients see Appendix Table B1). 


\section{$\underline{\text { Mortality Indexes }}$}

Table 5 presents mortality indexes for areas grouped by region or by population size. As in the utilization tables, all indexes have been adjusted for age and sex, and areas are weighted by the population of whites $65-84$ in those regions. The most striking result is the low mortality in Florida, which is slightly more than 10 percent below the U.S. average. Also below the U.S. average are Big Sky and West regions. The other four regions all have above average mortality with the Deep South experiencing the highest rate, more than 8 percent above the U.S. average. When areas are grouped by population size, the most notable result is that the mortality indexes are approximately the same across all the groups. Apparently despite the many socio-economic and other differences that exist between the large and the small metropolitan and nonmetropolitan areas, white death rates at ages 65-84 do not vary with population size.

The second and third columns of Table 5 allow comparisons of mortality between ages 65-74 and 75-84 (adjusted for sex mix). On the whole, the indexes are very similar. The regional rankings of mortality for the two age groups are almost identical. There is a slight tendency for the regional differentials to be smaller at ages 75-84 than at 65-74. When ageadjusted mortality rates for men and women are compared (columns 4 and 5 of Table 5), two substantial regional differentials are evident. In Deep South the relative mortality index is more than 7 percentage points higher for men than for women. In West, the index for men is 6 percentage points lower than for women.

$\underline{\text { Socioeconomic and Other Indexes }}$

Differentials in socioeconomic and other indexes across areas grouped by population size and region are shown in Table 6. Florida again stands out from the rest of the country in several 
respects. The percentage of high school dropouts is the lowest and real income the highest of all the regions. Only the West rivals Florida in having a low percentage of elderly with less than 12 years schooling. By contrast, the percent of dropouts is particularly high in the Deep South. Across the population size groups, the patterns for the percentage of high school dropouts and real income are quite systematic, with the former indexes rising and the latter falling as population size falls.

Regional differences in cigarette use and obesity are not as large as for the percentage with low education and have distinctive patterns of their own. Cigarette use is highest in the Deep South and lowest in the West. Obesity is highest in the North and WestSouth and lowest in Florida. Both cigarette use and obesity are lowest in the two largest population size groups and highest in the three other groups. In this respect, the pattern is similar to that for low educational attainment.

The reasons for including BLACK in the study will become apparent in discussion of the mortality regressions. For the present, we note that this variable has great regional variation, with extremely high rates in the Upper South and Deep South and extremely low rates in Big Sky and West. The index is much above average in the largest metropolitan areas and considerably below average in all the others.

The last variable in Table 6, pollution, is only measured for the MSAs greater than 100,000. The index for the West is 21 percent above the U.S. average; all other regions are below the U.S. average, with the lowest rate in Florida. Across population size groups, the pollution index declines steadily from the largest to the smallest. 


\section{Correlations Among Variables}

Some variables, such as low education and real income, are highly correlated with one another; the coefficient is -0.61 . Low education is also significantly correlated with cigarettes (0.38) and obesity (0.37). All three variables are significantly correlated with mortality: low education (0.49), cigarettes (0.44), and obesity (0.41). For a full matrix of correlation coefficients among all the variables see Appendix Table B-2

Regression Analysis: Utilization

In this section, we consider what factors appear to explain the various measures for utilization. All variables are in natural logs except for the region and population size dummy variables. All regressions are run across the 313 areas and across the 224 MSAs $>100,000$. At a theoretical level, the relation between low education and utilization is uncertain. It might be negative because individuals with less than 12 years of schooling might lack information about health care or might have less easy access to care. On the other hand, the relationship might be positive to the extent that those with less education are in worse health and require more care.

The predictive relation between income and utilization is also uncertain. If higher-income individuals are in better health, the relationship might be negative, but the relationship could be positive if there is a strong positive income elasticity of demand for care. Among other considerations, higher-income individuals are more likely to have private insurance that supplements Medicare.

Finally, because poor health usually results in increased utilization of health care, we expect mortality to be positively related to utilization to the extent that mortality is a good indicator of poor health. The relationship could be negative if this effect is outweighed by a 
reverse causality running from greater utilization to lower mortality. Because of the possibility of reverse causality, the parameter estimate for MORT should be regarded as a lower-bound estimate of the true coefficient.

Table 7 presents regression results for our measure of total utilization for three specifications. The first includes only the region and population size dummies, the second the two socioeconomic variables and mortality, and the third all the variables together. The results for the 224 MSAs are similar to those for the 313 areas and are available in Appendix Table B-3. Probably the most striking result is the large coefficient for MORT: With all variables included, it is $0.51(0.08)$. Under the reasonable assumption that the mortality rate is a good indicator of the health of the population, we infer that variation in health status across areas is a major determinant of health care utilization among whites $65-84$. Another notable result is the large increase in the Florida coefficient when the other variables are added to the regression. All the population size dummies have significant negative coefficients; that is, utilization is greater in MSAs larger than 500,000 than in any of the other areas. One likely interpretation is that patients in large metropolitan areas find it easier to obtain care (because of closer proximity to hospitals and physicians and the availability of a wide range of specialists).

Table 7 also presents regression results for inpatient utilization and outpatient utilization for the specification that includes all the variables. The coefficient for mortality is very large for inpatient care, but much smaller for outpatient care. For Florida, the reverse is true, with a huge coefficient for outpatient care and a much smaller (but still statistically significant coefficient) for inpatient care. In contrast, the Big Sky region has a large, statistically significant positive coefficient for inpatient care and a negative one for outpatient care. Clearly, regions differ both 
with regard to overall utilization as well as with respect to specific components of care. Neither low education nor real income are significantly related to utilization after controlling for the other variables. This result may reflect the offsetting theoretical considerations discussed above.

Table 8 presents similar regression results for medical and surgical admission and the three types of physician services. The coefficient for mortality is extremely large for medical admissions, no doubt reflecting the severe illness of many patients with neoplastic, cardiovascular, and cerebrovascular diseases who are admitted to medical services with little hope of altering the final outcome. The mortality coefficient for surgical admissions is less than half that for medical admissions, but still highly significant. In contrast, none of the three types of physician utilization has a mortality coefficient that is significantly different from zero.

The relationship between mortality and utilization reported in this paper is echoed in a study by Frohlich, Fransoo, and Roos (2001) of 12 communities in Winnipeg, Manitoba. They found that age-sex adjusted deaths before age 75 (their "Premature Mortality Rate") was positively correlated with most types of care. However, PMR was not correlated with visits to specialists and negatively correlated with "high profile" procedures such as MRIs, CABGs, hip and knee replacements, and preventive services.

The coefficients for Florida are particularly large for diagnostic and treatment services, smaller but still highly significant for evaluation and management, and smallest for hospital admissions. The Big Sky region has notably large negative mortality coefficients for evaluation and management and diagnostic services and a notably large positive coefficient for medical admissions. In comparisons of utilization across areas grouped by population size, the most striking result is the much higher utilization of evaluation and management and diagnostic 
services in MSAs $>500,000$ relative to those with 250-500,000 and especially areas with less than 250,000 or not MSAs. The only significant result for the socio-economic variables is a large positive relation between real income and treatment.

Because there may be some causality running from utilization to mortality, we also ran two-stage least squares regressions. The results are reported in Appendix Table B-5. The coefficients for predicted Ln mortality are typically much larger than in the OLS regressions, but the standard errors are also much larger, raising questions about the reliability of the estimates. $\underline{\text { Regression Analysis: Mortality }}$

In addition to the dummy variables for region and population size, the mortality regressions include the percentage of who did not finish high school and mean real income. Education and income have been shown to exhibit strong associations with mortality. Similarly, the harmful effects of cigarettes and obesity on health have been well established. Finally, we also include a variable measuring the fraction of the population that is African-American. We hypothesize a positive relationship between the percentage black and mortality for two reasons. First, this variable may be a marker for selective migration; migrants tend to be healthier than nonmigrants and they may have disproportionately opted for areas with low percentage black. A second set of reasons involve differences between the areas directly related to the percentage of African Americans. These differences might take the form of changes in the psychosocial environment that adversely affected health, or changes the quantity and mix of locally-provided services.

The mortality regression results are presented in Table 9 in three specifications similar to those shown for utilization. First we note that the $\mathrm{R}^{2} \mathrm{~s}$ are considerably higher for mortality than 
for utilization regressions. This is despite the fact that none of the population-size dummies are significantly different from zero either when just the geographical dummies are included or when the other variables are entered into the regression. This is unlike the utilization regressions where there is a significant differential between the largest areas and the others.

Inclusion of the other variables results in a significant reduction in the negative coefficients for Big Sky and West. There is also a small reduction in the negative coefficient for Florida. Nevertheless, even after controlling for all the other variables, Florida has a coefficient (relative to North) of $-0.096(0.01)$. It is the region with by far the lowest mortality. After controlling for the other variables, the highest regional mortality is in the Upper South.

Looking at the other variables we find that the percentage of high school dropouts has a positive coefficient until the geographic variable dummies are entered into the equation. Then the coefficient, while still positive, is not significantly different from zero. In the full regression real income has a negative coefficient which is significantly different from zero. Cigarette use has the expected positive coefficient which becomes larger when the geographic dummies are included. Obesity has the expected positive coefficient but it becomes smaller when the geographic dummies are included. Finally, the percent black has a positive coefficient and also remains relatively unchanged by inclusion of the geographic dummies. In the regressions across the 224 MSAs $>100,000$, shown in Appendix Table B-6, the results are similar. In addition, the pollution index has the expected positive coefficient and remains relatively unchanged in the presence of the geographic dummies.

Preliminary efforts to find an effect of income inequality were unsuccessful. In fact, in a variety of specifications, the coefficient for inequality was always negative. Similarly, we found 
no evidence of a relationship between religiousity and mortality whether measured by percent of religious adherents or by frequency of church attendance.

\section{Two Puzzles}

Here we consider two specific puzzles regarding patterns of mortality and utilization. The first puzzle is why the percentage of African-Americans in an area is positively related to the mortality of whites $65-84$. The second puzzle concerns the unusually low mortality and unusually high utilization in Florida relative to the rest of the country.

\section{Percent Black and Mortality}

Why should the mortality of whites $65-84$ be significantly positively related to the percent of the total population of an area that is black? The possible answers fall into two main categories. First, there may be health differences among the elderly whites that are correlated with BLACK, differences that are not accounted for by the other variables in the mortality regression. Such differences could arise as a result of selective in- and out-migration under the reasonable assumption that the movers are healthier than the stayers.

Second, there may be differences among the areas that are correlated with the white mortality. Some of these differences could take the form of fewer, locally provided services or a different mix of services that affect white mortality. Some differences could be psychosocial, such as racial tension or the fear of crime.

In order to learn more about the relationship between percent black and white mortality, we tested to see whether it is stronger in areas of high or low segregation. Using three CutlerGlaeser measures of segregation - centralization, isolation, and dissimilarity -- we divided the 
areas into equal groups of high segregation and low segregation and ran the basic mortality regression for each group. In none of the three trials did the coefficient for LnBLACK differ significantly between the high and the low segregation group. The mean coefficient for the three high segregation groups regressions was 0.018 and for the low segregation groups 0.022 . It appears that the relation between BLACK and MORT is about the same for areas of high and low segregation.

Another attempt to gain insight into the percent black effect produced more significant results. We divided the 224 MSAs $>100,000$ into two equal groups based on the percentage change in the population of whites $65-74$ between 1980 and 1990. The two groups are designated as "high growth" and "low growth" respectively. We then ran identical, full specification regressions for each group with the following results for the percent black coefficient: In the high growth areas, the coefficient is $0.051(0.010)$; in low growth areas, the coefficient is $0.008(0.009)$. The fact that percent black is not significantly related to mortality in the low growth areas suggests rejection of explanations that rely on differences among the areas. If such differences were causal, it is not easy to see why they would not also be operative in the low growth areas.

The large coefficient in the high growth areas suggests the possibility of unmeasured differences in selective migration, with the healthier (or more health conscious) migrants moving to the areas with lower percent blacks. However, if there is also a selective out-migration, why doesn't that produce a significant coefficient for BLACK in the low-growth areas? One possible answer is that much of the out-migration probably comes from a relatively few, very large areas such as New York, Chicago, Philadelphia, Boston and Detroit whereas the destination of the 
migrants is more dispersed with many going to areas with relatively small populations. This means that the effect of out-migration on the mortality rates of the remaining populations could be much less than the effect of in-migration on mortality rates in the high growth areas.

\section{Floridian Exceptionalism}

The data examined in this paper reveal that Florida is exceptional in three respects: (1) Among whites ages 65-84 utilization of care is much higher than in any other region and the differential increases when other variables are introduced as controls; (2) Mortality is by far the lowest in the country; (3) The positive relation between mortality and utilization which is evident in the rest of the country is not present in Florida.

Above average Medicare spending in Florida has been well established in previous studies, e.g., Wennberg and Cooper (1999). Our direct, detailed measures of utilization of services (rather than nominal or deflated Medicare spending) show that the Florida differential from the North of $0.193(0.021)$ when only population size is controlled for rises to $0.270(0.023)$ when education, real income, and mortality are included in the regression. Depending on the type of care, the size of the Florida differential varies enormously, from $0.058(0.029)$ for medical admissions to $0.499(0.049)$ for diagnostic services.

With respect to mortality the introduction of other variables reduces the negative coefficient for Florida from $-0.134(0.014)$ to $-0.096(0.015)$, but it still remains much larger than Big Sky, the region with the next lowest mortality $-0.026(0.012)$.

The combination of low mortality and high utilization is one of the most intriguing aspects of Floridian exceptionalism. When total utilization in Florida is regressed on mortality (controlling for education and income, all variables in logs) the coefficient is slightly negative, 
albeit not significantly different from zero. For the country as a whole, including Florida, the coefficient is $0.515(0.084)$; when Florida is excluded the coefficient rises to $0.636(0.092)$.

In order to gain some insight into Floridian exceptionalism, we examined each Florida MSA $>100,000$ separately as shown in Table 10. Predicted levels of utilization and mortality, obtained for each MSA from regressions that exclude Florida, are compared to actual levels, and the percent differential between actual and predicted calculated. We see that utilization is above predicted in every Florida MSA, but the differentials tend to be largest in the southern portion of the state. The mortality differentials also tend to be greatest in the southern MSAs; indeed the three most northern MSAs have actual mortality that is above the levels predicted from the regression. Two exceptions to the north vs. south differences are Daytona Beach and Ocala; these relatively northern MSAs have utilization and mortality differentials that resemble those of the southern MSAs.

Is Florida the only state with exceptional results? To answer this question we examined several other states that have been mentioned in health policy discussions as being unusual with respect to utilization or mortality or both. With methods analogous to those used to obtain the results presented in Table 10, we calculated percentage differentials between actual and predicted values for MSAs $>100,000$ in Arizona, Minnesota, Nevada, Oregon, and Utah. The results presented in Table 11, show some differentials, but nothing that comes close to challenging the characterization of Florida as "exceptional."

Another possible explanation for the low mortality rates in Florida is migration. Suppose that people who move to Florida are, on average, healthier than their counterparts who did not move. Given the large share of Florida residents who have moved from other states, one would 
expect that Florida would be a very healthy region simply because of this selection effect.

To test this hypothesis, we used the Medicare claims database for 1998 in Miami and Tampa, Florida, two regions with large populations of retirees. We first compared mortality rates of current residents of these areas as a function of where they were living three years previously. The sample was limited to nonblacks aged 68-84, with a cut off of 68 to ensure that we could match Medicare denominator information on zip code of residence from three years before when they were 65 . Migrants from the North experience a lower mortality probability (odds ratio equal to $0.80,95 \%$ confidence interval of 0.71 to 0.91 ), which is consistent with the hypothesis that migrants tend to be somewhat healthier than non-migrants. Migrants from other parts of the country, however, showed if anything slightly elevated mortality rates, although individually the effects were not significant. In any case, the overall influence of recent migrants (during the past 3 years) is minimal with regard to overall mortality rates because the proportion of recent movers - just 4.2 percent of the sample - is so small. Weighting the odds ratios by the proportion of people who migrated implies that the influence of this recent migration on overall mortality rates in the region is to reduce it by only about 0.5 percent.

The three-year window is probably too restrictive. Another approach is to use the first three digits of the individual's Social Security number. For this cohort, Social Security numbers were most likely issued while in their adult years, particularly during the 1940s through the 1960s when eligibility of Social Security gradually expanded to cover most employment sectors. This approach runs the risk of including in the "migrant" category individuals who may have been living in Florida for several decades. In any case, the results do not support the migration explanation; the one-third of the sample who received their Social Security number in Florida 
had slightly lower mortality than those who received their number in some other region.

If selective in-migration does not explain low mortality in the southern Florida MSAs, there are two other possibilities that need to be explored. First, the relatively benign climate for most of the year allows the elderly residents to pursue a great deal of physical activity including golf, tennis, swimming, walking, etc. Such activity is undoubtedly conducive to better health. Second, the low mortality in the southern Florida MSAs may result from a high level of social interaction among the elderly, as well as public services directed toward this very large voting bloc. Many of them live in communities populated primarily by other elderly where there is a great deal of eating out together, participating in social functions, and helping one another at times of physical or emotional stress.

Many social critics deplore age-restricted living arrangements and argue that the elderly would derive health and other benefits from interactions with members of younger generations. Reconciliation of these two points of view could lie in the classic quantity-quality trade-off. Holding the quantity of social interaction constant, the social critics may be correct that interactions across generations are more beneficial. But it also may be true that the greater quantity of social interactions in the elderly-segregated communities more than offsets the lower value of a given unit of interaction.

As is apparent from the above discussion, it is much easier to document Floridian exceptionalism than it is to explain it. We do not think that the high utilization is the cause of the low mortality because there is no support for this view in data for the rest of the country. When we tried utilization as a RHS variable in the mortality regression, the coefficient was positive in both OLS and 2SLS specifications. Nor do other studies find in comparisons between Florida 
and other regions that reductions in mortality are attributable to greater levels of care (Skinner, Fisher, and Wennberg, 2001). One "demand-driven" explanation for both high utilization and low mortality is that Floridians are very concerned about health, and this concern may also be expressed in exercise, diet, and other behaviors that are demonstrably linked to longevity, as well as increased demand for medical care.

\section{Summary}

This paper examines 313 U.S. areas for differences in medical care utilization and mortality of whites ages 65-84 in 1990. Areas are grouped into seven regions and five groups based on population size. Utilization is measured by direct count of detailed services, weighted by the national reimbursement for each service.

Probably the most noteworthy result of the utilization regressions is the extent to which cross-area variation in utilization is related to variation in mortality. For total utilization, the elasticity is $0.515(0.084)$ after controlling for region, population size of area, education and real income. This is a lower-bound estimate; the true coefficient would be larger to the extent that there is a negative relationship running from utilization of care to mortality. The elasticity is especially large for medical admissions, and especially small for physicians' diagnostic services and treatments. 
Also noteworthy is the extent to which the well-known propensity for higher utilization in Florida is even larger after controlling for socioeconomic variables and mortality. The coefficient for Florida is 40 percent (eight percentage points) higher when the other variables are in the regression.

A third result worthy of comment is the much higher utilization in MSAs of over 500,000 population relative to other areas. The average differential is about eight percent. Among the other areas there is no strong pattern related to population size. Similarly, there is no consistent pattern for the socioeconomic variables in their relationship to total utilization of care (although see McClellan and Skinner, 1999).

The mortality regressions produced several noteworthy results. First, we find no relationship between mortality and population size. Elderly residents of large MSAs enjoy no advantage in life expectancy over their peers who live in small MSAs or outside MSAs despite the well publicized differentials in the availability of medical care. Secondly, we find a very large negative coefficient for Florida. This region has by far the lowest mortality of any large region regardless of whether or not other variables are controlled for. Cigarette smoking, air pollution, and obesity have their expected positive coefficients. Lastly we note a robust positive relationship between percent black and mortality of whites 65-84. This relationship is particularly strong among areas with above average growth of the elderly population between 1980 and 1990. Among low growth areas, the coefficient is not significantly different from zero. This puzzle, and the exceptional results for Florida for utilization and mortality, require further investigation. 


\section{$\underline{\text { Endnotes }}$}

1. See for example Cutler, et al. (1998), Pardes, Manton, and Lander (1999), Currie and Gruber (1996), and Schneider (1999).

2. For an excellent review of some of this earlier literature, see Eisenberg (1986). More recently, see Wennberg and Cooper (1999), Escarce (1992), Green and Becker (1994), Welch, et al. (1994), Chassin, Brook, Park, et al. (1986), and references therein.

3. Cutler and Sheiner (1999) found that regional measures of the age/sex/race composition of the population explained 70 percent of regional differences in (agesex-race adjusted) Medicare expenditures. The factors providing the additional explanatory power included the age-composition of deaths in the region and the agespecific mortality rates. Here we raise a cautionary note about "ecological fallacy" in which aggregated data are used to make inferences about individual causal pathways, a concern of particular importance to any research on geographic variation (Susser, 1994a, 1994b). For example, the percentage of the elderly population that is Hispanic is predicted to increase regional Medicare expenditures (Cutler and Sheiner, 1999), yet average Medicare expenditures for Hispanics is roughly equal to expenditures for non-Hispanics.

4. See Evans, et al. (1984), Chappie and Lave (1982), and Ozkaynak and Thurston (1987).

5. See Kennedy, et al. (1996), Kaplan, et al. (1996), and Lynch, et al. (1998).

6. The Medicare records define residence as the location where the individual receives Social Security retirement checks. 
7. One other MSA $>100,000$, St. Cloud, Minnesota, was excluded from the study because of problems with the mortality data.

8. Some states do not have any MSAs with less than 100,000 or do not have any nonMSA residents.

\section{$\underline{\text { References }}$}

Allison, J. J., C. I. Kiefe, E. F. Cook, M. S. Gerrity, E. J. Orav, and R. Cenor. 1998. The association of physician attitudes about uncertainty and risk taking with resource use in a Medicare HMO." Medical Decision Making 18: 320-29.

Auster, Richard, Irving Leveson, and Deborah Saracheck. 1969. The production of health, an exploratory study. Journal of Human Resources 4 (4): 411-36.

Chappie, Mike and Lester Lave. 1982. The health effects of air pollution: A reanalysis. Journal of Urban Economics 12: 346-76.

Chassin, M.R. 1993. Explaining geographic variations: The enthusiasm mypothesis. Medical Care 31: YS37-44.

Chassin, M.R., R. H.Brook, R. E.Park, et al. 1986. Variations in the use of medical and surgical practices by the Medicare population. New England Journal of Medicine 314: 285-90.

Chau, Derek, Elliott Fisher, and Jonathan Skinner. 2001. The importance of regional practice style in a cohort of elderly hip fracture patients. Hanover, NH: Dartmouth Medical School. Mimeograph.

Currie, Janet, and Jonathan Gruber. 1996. Saving babies: The efficacy and cost of recent changes in the Medicaid eligibility of pregnant women. Journal of Political Economy 104 (6) (December): 1263-96.

Cutler, David, Mark McClellan, Joseph Newhouse, and Dahlia Remler. 1998. Are medical prices declining?: Evidence from heart attack treatments. Quarterly Journal of Economics 113 (4) (November): 991-1024.

Cutler, David, and Louise Sheiner. 1999. The geography of Medicare. American Economic Review 89 (2) (May): 228-33.

Deaton, Angus. 2001. Inequalities in income and inequalities in health. In Inequality in 
America, ed. Finis Welch. Chicago, IL: University of Chicago Press (forthcoming).

Deaton, Angus, and Darren Lubotsky. 2001. Inequality and race in American cities and states. NBER Working Paper no. 8370. Cambridge, Mass: National Bureau of Economic Research.

Deaton, Angus, and Christina Paxson. 1999. Mortality, education, income, and inequality among American cohorts," NBER Working Paper no. 7140. Cambridge, Mass: National Bureau of Economic Research, May.

Deaton, Angus, and Christina Paxson. 2001. Mortality, income, and income inequality over time in Britain and the United States, NBER Working Paper no. 8534. Cambridge, Mass: National Bureau of Economic Research.

Eisenberg, John A. 1986. Doctors' decisions and the cost of medical care: The reasons for doctors' practice patterns and ways to change them. Ann Arbor, MI: Health Administration Press Perspectives.

Escarce, Jose. 1992. Explaining the association between surgeon supply and utilization. Inquiry 29: 403-15.

Escarce, Jose. 1993. Medicare patients' use of overpriced procedures before and after the Omnibus Budget Reconciliation Act of 1987. American Journal of Public Health 83: 349-55.

Evans, J.S., et al. 1984. Cross-sectional mortality studies and air pollution risk assessment. Environmental International 10: 55-83.

Fisher, Elliott S., Etoile Pinder, Daniel Gottlieb, and Therese Stukel. 2001. Associations between regional variations in Medicare expenditures, access to care, and patient satisfaction. Hanover, NH: Dartmouth Medical School. Mimeograph.

Folland, Sherman, and Miron Stano. 1989. Sources of small area variation in the use of medical care. Journal of Health Economics 8: 85-107.

Franks, P., G. C. Williams, J. Zwanziger, C. Mooney, M. Sorbero. 2000. Why do physicians vary so widely in their referral rates? Journal of General Internal Medicine 15: 163-68.

Frohlich, N. R. Fransoo, and N. Roos. 2001. Indicators of health status and health service use for the Winnipeg Regional Health Authority. Winnipeg, Manitoba: Manitoba Center for Health Policy and Evaluation; Department of Community Health Sciences; Faculty of Medicine; University of Manitoba, March. 
Fuchs, V. R., and Marcia J. Kramer. 1986. Determinants of expenditures for physicians' services in the United States, 1948-1968. In The health economy, ed. Victor R. Fuchs. Cambridge, Mass: Harvard University Press.

Gray, B. H., and W. J. McNerney. 1986. For-profit enterprise in health care: The Institute of Medicine Study. New England Journal of Medicine 314:1523-28.

Green, L. A., and M. P. Becker. 1994. Physician decision making and variation in hospital admission rates for suspected acute cardiac myocardial infarction. A tale of two towns. Medical Care 32: 1086-97.

Hadley, Jack. 1988. Medicare spending and mortality rates of the elderly. Inquiry 25: 485-93.

Kaplan, George A., et al. 1996. Inequality in income and mortality in the United States: Analysis of mortality and potential pathways. British Medical Journal 312: 999-1003.

Kennedy, Bruce P., et al. 1996. Income distribution and mortality: Cross-sectional ecological study of the Robin Hood Index in the United States. British Medical Journal 312:1004-07.

Kessler, Daniel, and Mark McClellan. 1999. Is hospital competition socially wasteful? NBER Working Paper no. 7266. Cambridge, Mass: National Bureau of Economic Research, July.

Lin, Ge, "A regional assessment of elderly disability in the U.S." 2000. Social Science and Medicine, 50: 1015-24.

Lynch, John W., et al. 1998. Income distribution and mortality in metropolitan areas of the United States. American Journal of Public Health 88 (7): 1074-80.

McClellan, Mark, and Jonathan Skinner. 1997. The incidence of Medicare, NBER Working Paper, revised 2000.

McClellan, Mark, and Jonathan Skinner. 1999. Medicare reform: Who pays and who benefits? Health Affairs 18 (1) (Jan/Feb): 48-62.

Ozkaynak, Haluk, and George D. Thurston. 1987. Associations between 1980 U.S. mortality rates and alternative measures of airborne particle concentration. Risk Analysis 7 (4): 449-61.

Pardes, H., K. G. Manton, E. S. Lander, et al. 1999. Effects of medical research on health care and the economy. Science 283 (January 1): 36-37.

Pearson, S. D., L. Goldman, E. J. Orav, et al. 1995. Triage decisions for emergency department patients with chest pain: Do physicians' risk attitudes make the difference? Journal of General Internal Medicine 10: 557-64. 
Schneider, E. L. 1999. Aging in the third millennium. Science 283 (February 5): 796-97.

Selby, J. V., K. Grumback, C. P. Quesenberry, et al. 1999. Differences in resource use and costs of primary care in a large HMO according to physician specialty. Health Services Research 34: 503-18.

Silver, Morris. 1972. An econometric analysis of spatial variations in mortality rates by race and sex. In Essays in the economics of health and medical care, ed. Victor R. Fuchs. New York, NY: Columbia University Press.

Silverman, Elaine, Jonathan Skinner, and Elliott Fisher. 1999. The association between forprofit hospital ownership and increased Medicare spending. New England Journal of Medicine 341 (August 5): 420-26.

Skinner, Jonathan, and Elliott Fisher. 1997. Regional disparities in Medicare expenditures: An opportunity for Medicare reform. National Tax Journal 50 (September): 413-25.

Skinner, Jonathan, Elliott Fisher, and John Wennberg. 2001. The efficiency of Medicare. NBER Working Paper no. 8395. Cambridge, Mass: National Bureau of Economic Research.

Susser, M. 1994a. The logic in ecological: I. The logic of analysis. American Journal of Public Health 84: 825-29.

Susser, M. 1994b. The logic in ecological: II. The logic of design. American Journal of Public Health 84: 830-35.

Taylor, D. H., Jr, D. J. Whellan, F. A. Sloan. 1999. Effects of admission to a teaching hospital on the cost and quality of care for Medicare beneficiaries. New England Journal of Medicine 340: 293-99.

Wennberg, John E, Benjamin A. Barnes, and Michael Zubkoff. 1982. Professional uncertainty and the problem of supplier-induced demand. Social Science and Medicine 16: 811-24.

Wennberg John E., and Megan M. Cooper. 1999. The quality of medical care in the United States: a report on the Medicare Program. The Dartmouth atlas of health care in the United States. Chicago, IL: American Health Association Press.

Wennberg, John E., and Megan M. Cooper. 1996. The Dartmouth atlas of health care in the United States. Chicago, IL: American Health Association Press.

Wennberg, John E., Elliott Fisher, and Jonathan Skinner. 2001. Geography and the debate over Medicare reform. Health Affairs. Forthcoming. 
Wright, James G., G. A. Hawker, and C. Bombardier, et al. 1999. Physician enthusiasm as an explanation for area variation in the utilization of knee replacement surgery. Medical Care 37: 946-56. 
Table 1. Names, Definitions, and Sources of Variables

\begin{tabular}{|c|c|c|}
\hline TOTUTIL & $\begin{array}{l}\text { Total health care utilization per white Medicare enrollee } 65- \\
84^{\text {a }}, 1989-1991\end{array}$ & HCFA $^{\text {efg }}, 1989-1991$ \\
\hline INUTIL & $\begin{array}{l}\text { Inpatient utilization (including institutional reimbursement an } \\
\text { physician services), per white Medicare enrollee 65-84, 1989- } \\
1991\end{array}$ & HCFA $^{\text {efg }}, 1989-1991$ \\
\hline OUTUTIL & $\begin{array}{l}\text { Outpatient utilization (including institutional reimbursement } \\
\text { for same day services, physician and misc. services) per white } \\
\text { Medicare enrollee } 65-84^{\mathrm{a}}, 1989-1991\end{array}$ & HCFA $^{\text {efg }}, 1989-1991$ \\
\hline TOTADM & $\begin{array}{l}\text { Weighted total hospital admissions, 1989-1991, per white } \\
\text { Medicare enrollee } 65-84^{\text {a }}, 1989-1991\end{array}$ & HCFA $^{\text {ef }}, 1989-1991$ \\
\hline MEDADM & $\begin{array}{l}\text { Weighted hospital medical admissions, per white Medicare } \\
\text { enrollee } 65-84^{\text {a }}, 1989-1991\end{array}$ & HCFA $^{\text {ef }}, 1989-1991$ \\
\hline SURGADM & $\begin{array}{l}\text { Weighted hospital surgical admissions, per white Medicare } \\
\text { enrollee } 65-84^{\text {a }}, 1989-1991\end{array}$ & HCFA $^{\text {ef }}, 1989-1991$ \\
\hline TOTPHYS & $\begin{array}{l}\text { Total physician utilization (inpatient and outpatient), per white } \\
\text { Medicare enrollee } 65-84^{\mathrm{a}}, 1989-1991\end{array}$ & $\mathrm{HCFA}^{\mathrm{eg}}, 1989-1991$ \\
\hline EANDM & $\begin{array}{l}\text { Physician utilization for evaluation and management services } \\
\text { (inpatient and outpatient), per white Medicare enrollee 65- } \\
84^{\text {a }}, 1989-1991\end{array}$ & $\mathrm{HCFA}^{\mathrm{eg}}, 1989-1991$ \\
\hline DIAG & $\begin{array}{l}\text { Physician utilization for diagnosis (inpatient and outpatient), } \\
\text { per white Medicare enrollee } 65-84^{\mathrm{a}}, 1989-1991\end{array}$ & HCFA $^{\text {eg }}, 1989-1991$ \\
\hline TREAT & $\begin{array}{l}\text { Physician utilization for procedures/treatment (inpatient and } \\
\text { outpatient), per white Medicare enrollee } 65-84^{\mathrm{a}}, 1989-1991\end{array}$ & HCFA $^{\mathrm{eg}}, 1989-1991$ \\
\hline MORT & Deaths per 1,000 , whites $65-84^{\text {a }}$, average $1989-1991$ & HCFA $^{\mathrm{e}}, 1989-1991$ \\
\hline LOED & $\begin{array}{l}\text { Percent of whites } 65-84^{\mathrm{a}} \text { with less than } 12 \text { years of schooling, } \\
1990\end{array}$ & $\begin{array}{l}\text { U.S. Census of } \\
\text { Population, } 1990\end{array}$ \\
\hline REALINC & $\begin{array}{l}\text { Mean income for whites ages } 65-84^{\mathrm{a}} \text { (1990) deflated by cost } \\
\text { of living index (1991) }\end{array}$ & $\begin{array}{l}\text { U.S. Census of } \\
\text { Population, } 1990\end{array}$ \\
\hline CIGS & Per capita sales by state (packs), average 1984-1989 & Tobacco Institute, 1998 \\
\hline OBESE & Percent obese ${ }^{\mathrm{d}}$ by state, adjusted for race, 1991 & Mokdad et al, 1999 \\
\hline POLUTN & $\begin{array}{l}\text { Mean PM-10 concentration (particulate matter } 10 \text { microns or } \\
\text { smaller in diameter, } \mu \mathrm{g} / \mathrm{m}^{3} \text { ), average } 1990-1994\end{array}$ & Shprentz, 1996 \\
\hline BLACK & Percent of total population black, 1990 & $\begin{array}{l}\text { Area Resource File, } \\
1992\end{array}$ \\
\hline
\end{tabular}




\section{Table 1. Names, Definitions, and Sources of Variables}

Notes:

a) Standardized for age and sex

b) HCFA 5\% samples (Medpar, Outpatient SAF, BMAD, HHA SAF, Hospice SAF)

c) COL predicted from a regression of U.S. Chamber of Commerce cost-of-living index for 109

metropolitan areas (1991) on standardized wage index and median property values (1990)

d) Body mass index (weight divided by square of height) $\geq 30 \mathrm{~kg} / \mathrm{m}^{2}$

e) Hiskew $20 \%$ random sample

f) MEDPAR 20\% random sample

g) BMAD 5\% random sample

\section{References:}

Area Resource File, Office of Data Analysis and Management, U.S. Bureau of Health Professions, March 1992.

Data Users Reference Guide, Health Care Financing Administration, Baltimore, MD, January, 2000. Health Insurance Skeleton Eligibility Write-Off File Medicare Provider Analysis and Review File Physician/Supplier Standard Analytic File Home Health SAF

Hospice SAF

Outpatient Hospital SAF

Mokdad, A.H. Serdula, M.K. Dietz, W.H. Bowman, B.A. Marks, J.S. Koplan, J.P. "The Spread of the Obesity Epidemic in the United States, 1991-1998", JAMA, October 27, 1999 - Vol 282, No. 16.

Part B Medicare Annual Data (BMAD) Procedure File, Health Care Financing Administration, Five Percent Random Sample of Medicare Enrollment Data, 1989-1991.

Shprentz, D.S. "Breath-taking: Premature Mortality Due to Particulate Air Pollution in 239 American Cities", Natural Resources Defense Council, May 1996.

http://www.igc.apc.org/nrdc/nrdc/nrdcpro

"The Tax Burden on Tobacco", Tobacco Institute, Washington, D.C., Vol. 33, Historical Compilation 1998.

U.S. News Online (1997-98). http://www.usnews.com/usnews/edu/beyond/bcmed.htm 


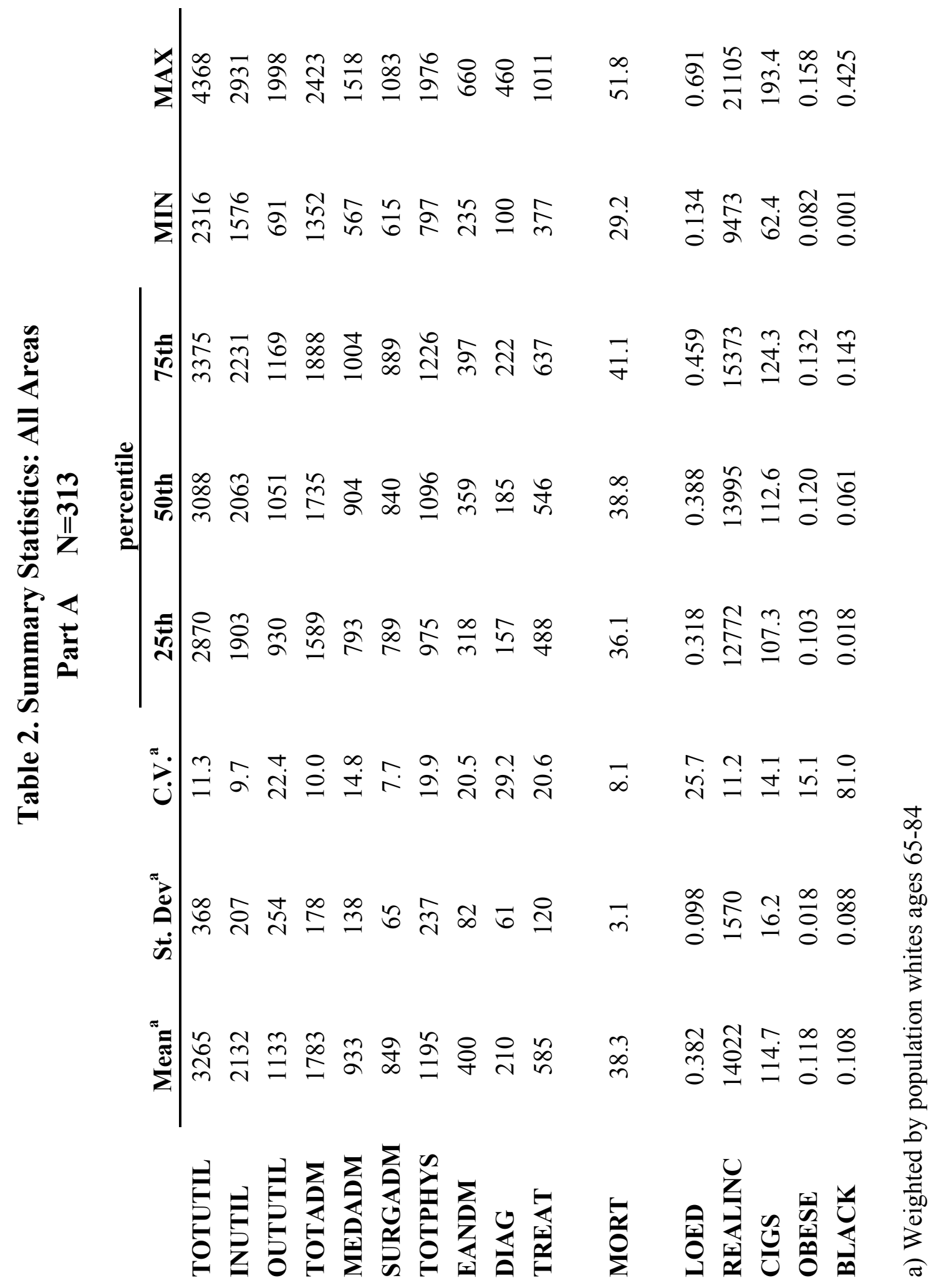




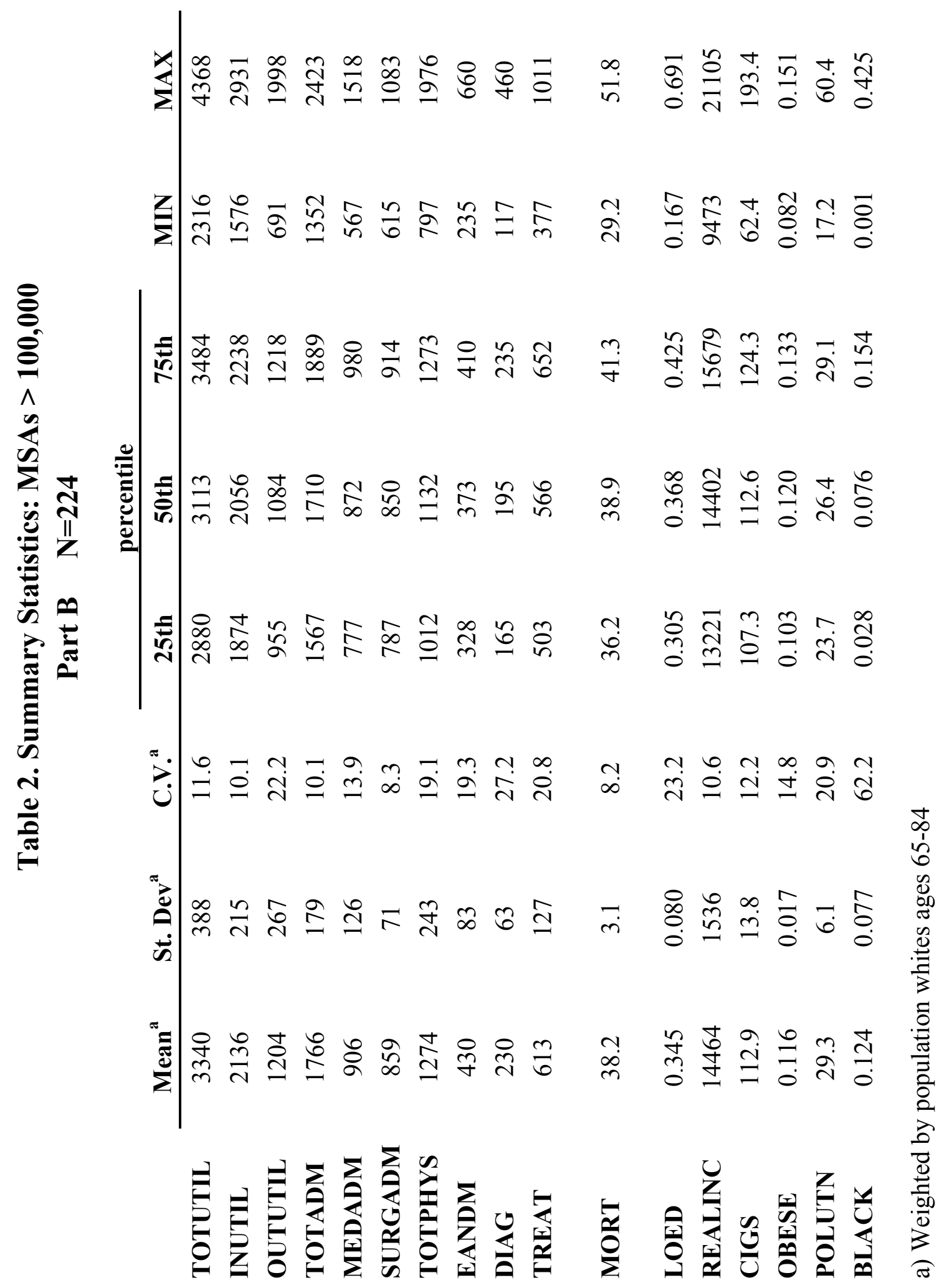




\section{Table 3. Utilization Indexes ${ }^{a}$ for Areas ${ }^{b}$ Grouped by Region and Population Size}

$$
\text { (US=100) }
$$

$\underline{\text { Part A } \quad \mathrm{N}=313 \text { All Areas }}$

TOTUTIL INUTIL $^{c}$ OUTUTIL $^{d}$

\section{Region}

North

Upper South

96.8

97.8

95.1

101.2

102.4

98.9

Deep South

102.7

104.8

98.6

Florida

117.5

97.4

155.3

101.8

104.9

95.9

Big Sky

91.8

99.3

77.7

West

101.8

100.3

104.5

\section{Population size}

$>500 \mathrm{~K}$
$250-500 \mathrm{~K}$
$100-250 \mathrm{~K}$
$<100 \mathrm{~K}$
Not MSA

U.S. Expenditure

per enrollee

\section{Region}

North

Upper South

Deep South

Florida

West South

Big Sky

West

$\begin{array}{ccc}103.6 & 101.4 & 107.9 \\ 99.5 & 95.8 & 106.4 \\ 94.8 & 95.7 & 93.2 \\ 96.9 & 100.3 & 90.5 \\ 94.9 & 99.2 & 86.7\end{array}$

3265

2132

1133

$\begin{array}{ccc}\text { Part B } & \text { N=224 } & \text { MSAs }>100,000 \\ \text { TOTUTIL } & \text { INUTIL }^{c} \quad \text { OUTUTIL }^{d}\end{array}$

U.S. Expenditure per enrollee

$\begin{array}{lc}96.1 & 98.1 \\ 100.1 & 99.2 \\ 100.5 & 102.3 \\ 116.0 & 97.2 \\ 101.6 & 104.9 \\ 93.1 & 101.6 \\ 102.2 & 102.2 \\ & \\ 3340 & 2136 \\ \text { ized for age and sex } \\ \text { d by population whites ages } 65-84 \\ \text { d physician }\end{array}$

92.5

101.8

97.1

149.3

95.8

78.1

102.0

a) All indexes standardized for age and sex

b) Area values weighted by population whites ages 65-84

c) Includes hospital and physician

d) Includes hospital, physician and misc. services 
Table 4. Hospital Admissions Indexes for Areas Grouped by Region and Population Size (US=100)

Part A N=313 All Areas

$\begin{array}{lccccccc} & \text { TOTADM } & \text { MEDADM } & \text { SURGADM } & \text { TOTPHYS }^{\mathbf{a}} & \text { EANDM }^{\mathbf{a}} & \text { DIAG }^{\mathbf{a}} & \text { TREAT }^{\mathbf{a}} \\ \begin{array}{l}\text { Region } \\ \text { North }\end{array} & 98.5 & 98.8 & 98.2 & 94.0 & 100.1 & 95.4 & 89.3 \\ \text { Upper South } & 102.2 & 105.4 & 98.8 & 98.5 & 99.6 & 95.5 & 98.9 \\ \text { Deep South } & 107.3 & 113.5 & 100.4 & 92.7 & 91.0 & 91.0 & 94.5 \\ \text { Florida } & 92.3 & 84.8 & 100.7 & 142.0 & 126.6 & 162.8 & 145.0 \\ \text { West South } & 105.8 & 107.0 & 104.4 & 97.5 & 91.7 & 99.0 & 101.0 \\ \text { Big Sky } & 101.1 & 101.9 & 100.2 & 85.3 & 80.5 & 77.2 & 91.6 \\ \text { West } & 97.8 & 94.4 & 101.4 & 111.2 & 110.3 & 104.9 & 114.0 \\ & & & & & & & \\ \text { Population size } & & & & & & & \\ >\text { > 500 K } & 100.0 & 98.4 & 101.7 & 109.0 & 111.6 & 112.8 & 105.8 \\ \text { 250-500 K } & 95.4 & 91.1 & 100.1 & 102.7 & 96.6 & 104.4 & 106.2 \\ \text { 100-250 K } & 96.2 & 94.0 & 98.6 & 92.4 & 87.7 & 92.1 & 95.7 \\ <100 \text { K } & 102.1 & 105.2 & 98.6 & 89.5 & 88.5 & 83.3 & 92.4 \\ \text { Not MSA } & 101.6 & 105.5 & 97.3 & 86.3 & 84.2 & 80.5 & 89.8 \\ \text { U.S. Expenditure } & & & & & & & \end{array}$

$\underline{\text { Part B } \quad \mathrm{N}=224 \text { MSAs }>100,000}$

$\begin{array}{lccccccc} & \text { TOTADM } & \text { MEDADM } & \text { SURGADM } & \text { TOTPHYS }^{\mathbf{a}} & \text { EANDM }^{\mathbf{a}} & \text { DIAG }^{\mathbf{a}} & \text { TREAT }^{\mathbf{a}} \\ \begin{array}{lccccc}\text { Region } \\ \text { North }\end{array} & 99.4 & 100.8 & 98.0 & 91.7 & 97.7 & 93.3 & 86.9 \\ \text { Upper South } & 97.7 & 98.1 & 97.3 & 102.1 & 100.0 & 101.6 & 103.8 \\ \text { Deep South } & 104.6 & 106.7 & 102.2 & 91.5 & 86.4 & 90.1 & 95.6 \\ \text { Florida } & 92.6 & 86.3 & 99.2 & 136.4 & 121.7 & 153.6 & 140.3 \\ \text { West South } & 105.7 & 105.9 & 105.6 & 97.6 & 91.1 & 97.1 & 102.3 \\ \text { Big Sky } & 103.3 & 105.2 & 101.4 & 85.3 & 81.7 & 77.6 & 90.8 \\ \text { West } & 100.3 & 99.0 & 101.7 & 108.3 & 108.1 & 100.7 & 111.3 \\ \begin{array}{l}\text { U.S. Expenditure } \\ \text { per enrollee }\end{array} & 1766 & 906 & 859 & 1274 & 430 & 230 & 613\end{array}$

a) Includes inpatient and outpatient

Note: See footnotes $a$ and $b$ to Table 4 
Table 5. Mortality Indexes for Areas Grouped by Region and Population Size (US=100)

$\underline{\text { Part A N=313 All Areas }}$

$\begin{array}{lccccc}\text { Region } & \text { MORT } & \mathbf{6 5 - 7 4} & \mathbf{7 5 - 8 4} & \text { Men } & \text { Women } \\ \text { North } & 102.2 & 102.3 & 102.0 & 101.9 & 102.5 \\ \text { Upper South } & 106.4 & 107.4 & 105.5 & 106.3 & 106.5 \\ \text { Deep South } & 108.5 & 109.7 & 107.5 & 112.0 & 104.5 \\ \text { Florida } & 89.5 & 90.0 & 89.2 & 90.3 & 88.7 \\ \text { West South } & 103.9 & 104.0 & 103.8 & 104.3 & 103.4 \\ \text { Big Sky } & 94.0 & 93.2 & 94.6 & 95.4 & 92.4 \\ \text { West } & 94.0 & 92.8 & 94.9 & 91.0 & 97.3 \\ \text { Population size } & & & & & \\ \quad>\text { 500 K } & 99.8 & 99.7 & 99.9 & 98.7 & 101.1 \\ \text { 250-500 K } & 98.1 & 97.1 & 98.8 & 97.8 & 98.4 \\ \text { 100-250 K } & 100.7 & 100.6 & 100.8 & 101.4 & 100.0 \\ \quad<100 \text { K } & 101.7 & 102.0 & 101.4 & 102.8 & 100.4 \\ \quad \text { Not MSA } & 99.8 & 100.1 & 99.5 & 101.6 & 97.7 \\ \text { Deaths per 1,000 } & 38.31 & 26.16 & 59.68 & 48.95 & 30.72\end{array}$

$\underline{\text { Part B } \quad \mathrm{N}=224 \mathrm{MSAs}>\mathbf{1 0 0 , 0 0 0}}$

$\begin{array}{lccccc}\text { Region } & \text { MORT } & \mathbf{6 5 - 7 4} & \mathbf{7 5 - 8 4} & \text { Men } & \text { Women } \\ \text { North } & 102.9 & 103.4 & 102.6 & 103.1 & 102.8 \\ \text { Upper South } & 104.4 & 103.8 & 104.8 & 103.6 & 105.2 \\ \text { Deep South } & 108.7 & 110.2 & 107.6 & 112.0 & 105.1 \\ \text { Florida } & 88.9 & 89.8 & 88.2 & 90.5 & 87.1 \\ \text { West South } & 104.7 & 103.5 & 105.6 & 105.4 & 103.9 \\ \text { Big Sky } & 97.7 & 96.8 & 98.3 & 98.1 & 97.2 \\ \text { West } & 94.5 & 93.4 & 95.3 & 92.2 & 97.1 \\ \text { Deaths per 1,000 } & 38.20 & 26.03 & 59.60 & 48.41 & 30.92\end{array}$

Note: See footnotes a and $b$ to Table 4 
Table 6. Socioeconomic and Other Indexes for Areas Grouped by Region and Population Size (US=100)

$\underline{\text { Part A } \quad \mathrm{N}=313 \text { All Areas }}$

$\begin{array}{lccccc}\text { Region } & \text { LOED }^{\text {a }} & \text { REALINC }^{\text {a }} & \text { CIGS } & \text { OBESE } & \text { BLACK } \\ \quad \text { North } & 102.2 & 95.6 & 102.0 & 108.0 & 94.1 \\ \text { Upper South } & 109.6 & 107.5 & 105.9 & 95.9 & 167.8 \\ \text { Deep South } & 131.0 & 96.3 & 118.3 & 97.6 & 195.2 \\ \text { Florida } & 73.3 & 112.3 & 106.4 & 83.0 & 121.6 \\ \text { West South } & 115.4 & 104.0 & 97.3 & 105.3 & 126.0 \\ \text { Big Sky } & 100.1 & 104.1 & 94.8 & 101.0 & 38.5 \\ \text { West } & 75.9 & 100.7 & 83.9 & 88.1 & 48.9 \\ \text { Population size } & & & & & \\ >\text { 500 K } & 88.4 & 103.3 & 97.9 & 98.0 & 125.5 \\ \text { 250-500 K } & 95.1 & 103.1 & 99.4 & 98.9 & 78.8 \\ \text { 100-250 K } & 100.4 & 101.8 & 100.9 & 102.2 & 74.1 \\ <100 \text { K } & 116.0 & 94.0 & 104.1 & 102.8 & 77.4 \\ \text { Not MSA } & 119.6 & 94.2 & 102.2 & 102.9 & 68.3 \\ \text { U.S. average } & 0.382 & 14,022 & 114.7 & 0.118 & 0.108\end{array}$

$\underline{\text { Part B } \quad \mathrm{N}=224 \mathrm{MSAs}}>\mathbf{1 0 0 , 0 0 0}$

\section{LOED $^{\text {a }}$ REALINC $^{\mathrm{a}}$ CIGS OBESE BLACK POLUTN}

\section{Region}

North

Upper South

109.7

94.8

102.6

109.1

106.6

97.2

$\begin{array}{llllll}95.6 & 118.0 & 107.1 & 90.5 & 203.0 & 90.2\end{array}$

Deep South

121.4

101.9

118.3

98.3

168.3

99.0

Florida

79.8

108.5

108.1

84.2

105.3

81.7

West South

108.8

97.6

107.9

118.9

87.3

Big Sky

94.9

103.8

98.8

97.3

64.7

96.4

West

80.9

$99.0 \quad 85.4$

89.1

49.2

120.8

U.S. average

$0.345 \quad 14,464 \quad 112.9$

0.116

0.124

29.3

a) Standardized for age and sex

Note: See footnote b to Table 4 
Table 7. Utilization Regression Results,

OLS, N=313 (Standard error in parenthesis)

$$
\mathbf{R}^{2}
$$

Upper South

Deep South

Florida

West South

Big Sky

West

250-500

100-250

$<100$

Not MSA

Ln LOED

Ln REALINC

Ln MORT

Intercept
LnTOTUTIL

$\begin{array}{lll}0.366 & 0.090 & 0.450\end{array}$

$$
0.053
$$$$
(0.025)
$$

0.029

$(0.025)$

0.080

$(0.018)$

0.040

(0.019)

0.193

(0.021)

0.270

(0.023)

0.064

(0.019)

0.049

(0.020)

$-0.028$

(0.018)

0.014

(0.019)

0.038

(0.015)

0.091

(0.017)

$-0.064$

$(0.020)$

$-0.058$

(0.019)

$-0.090$

(0.021)

$-0.090$

(0.020)

$-0.061$

(0.016)

$-0.060$

(0.016)

$-0.082$

(0.014)

$-0.079$

(0.015)

$\begin{array}{ll}-0.080 & 0.036\end{array}$

$(0.033) \quad(0.036)$

$0.151 \quad 0.026$

$0.072) \quad(0.074)$

$$
\begin{array}{cc}
0.361 & 0.515 \\
(0.086) & (0.084)
\end{array}
$$

8.086
$(0.009)$

5.247

5.986

(0.763) $\frac{\text { Ln INUTIL }}{0.343} \frac{\text { Ln OUTUTIL }}{0.652}$

$\begin{array}{cc}0.022 & 0.036 \\ (0.024) & (0.037)\end{array}$

0.027

0.063

(0.018)

(0.027)

0.113

0.496

(0.022)

(0.034)

0.064

0.021

(0.019)

(0.029)

0.092

$-0.148$

(0.018)

(0.028)

0.094

0.087

(0.016)

(0.025)

$-0.053$

$-0.065$

(0.018)

(0.027)

$-0.074$

$-0.118$

(0.019)

(0.029)

$-0.027$

$-0.117$

(0.015)

(0.024)

$-0.041$

$-0.152$

(0.015)

(0.022)

0.043

0.020

(0.034)

(0.052)

$-0.032$

0.147

(0.071)

(0.108)

0.694

0.216

(0.080)

(0.122)

5.458

4.853

(0.729) 
Table 8. Utilization Regression Results by Type of Service, OLS, N=313

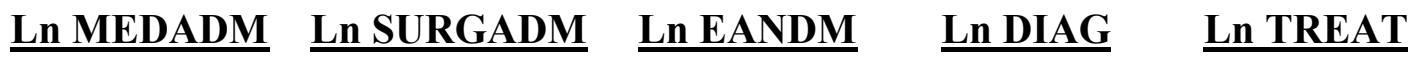

\begin{tabular}{|c|c|c|c|c|c|}
\hline $\mathbf{R}^{2}$ & 0.526 & 0.261 & 0.549 & 0.570 & 0.609 \\
\hline Upper South & $\begin{array}{c}0.024 \\
(0.031)\end{array}$ & $\begin{array}{l}-0.019 \\
(0.020)\end{array}$ & $\begin{array}{c}0.035 \\
(0.040)\end{array}$ & $\begin{array}{c}0.025 \\
(0.054)\end{array}$ & $\begin{array}{c}0.076 \\
(0.037)\end{array}$ \\
\hline Deep South & $\begin{array}{c}0.046 \\
(0.023)\end{array}$ & $\begin{array}{c}0.001 \\
(0.015)\end{array}$ & $\begin{array}{l}-0.029 \\
(0.030)\end{array}$ & $\begin{array}{c}0.033 \\
(0.040)\end{array}$ & $\begin{array}{c}0.064 \\
(0.028)\end{array}$ \\
\hline Florida & $\begin{array}{c}0.058 \\
(0.029)\end{array}$ & $\begin{array}{c}0.077 \\
(0.018)\end{array}$ & $\begin{array}{c}0.264 \\
(0.037)\end{array}$ & $\begin{array}{c}0.499 \\
(0.049)\end{array}$ & $\begin{array}{c}0.464 \\
(0.034)\end{array}$ \\
\hline West South & $\begin{array}{c}0.063 \\
(0.025)\end{array}$ & $\begin{array}{c}0.051 \\
(0.016)\end{array}$ & $\begin{array}{l}-0.030 \\
(0.032)\end{array}$ & $\begin{array}{c}0.080 \\
(0.042)\end{array}$ & $\begin{array}{c}0.112 \\
(0.029)\end{array}$ \\
\hline Big Sky & $\begin{array}{c}0.139 \\
(0.024)\end{array}$ & $\begin{array}{c}0.064 \\
(0.015)\end{array}$ & $\begin{array}{l}-0.115 \\
(0.030)\end{array}$ & $\begin{array}{c}-0.138 \\
(0.041)\end{array}$ & $\begin{array}{c}0.042 \\
(0.028)\end{array}$ \\
\hline West & $\begin{array}{c}0.081 \\
(0.021)\end{array}$ & $\begin{array}{c}0.067 \\
(0.013)\end{array}$ & $\begin{array}{c}0.078 \\
(0.027)\end{array}$ & $\begin{array}{c}0.062 \\
(0.036)\end{array}$ & $\begin{array}{c}0.242 \\
(0.025)\end{array}$ \\
\hline 250-500 & $\begin{array}{l}-0.067 \\
(0.023)\end{array}$ & $\begin{array}{c}-0.013 \\
(0.015)\end{array}$ & $\begin{array}{l}-0.156 \\
(0.030)\end{array}$ & $\begin{array}{c}-0.140 \\
(0.040)\end{array}$ & $\begin{array}{l}-0.039 \\
(0.028)\end{array}$ \\
\hline $100-250$ & $\begin{array}{l}-0.087 \\
(0.025)\end{array}$ & $\begin{array}{l}-0.036 \\
(0.016)\end{array}$ & $\begin{array}{l}-0.213 \\
(0.032)\end{array}$ & $\begin{array}{l}-0.184 \\
(0.042)\end{array}$ & $\begin{array}{c}-0.083 \\
(0.029)\end{array}$ \\
\hline$<100$ & $\begin{array}{c}0.007 \\
(0.020)\end{array}$ & $\begin{array}{c}-0.023 \\
(0.013)\end{array}$ & $\begin{array}{l}-0.196 \\
(0.026)\end{array}$ & $\begin{array}{c}-0.254 \\
(0.034)\end{array}$ & $\begin{array}{l}-0.060 \\
(0.024)\end{array}$ \\
\hline Not MSA & $\begin{array}{c}0.009 \\
(0.019)\end{array}$ & $\begin{array}{l}-0.039 \\
(0.012)\end{array}$ & $\begin{array}{l}-0.235 \\
(0.024)\end{array}$ & $\begin{array}{c}-0.280 \\
(0.032)\end{array}$ & $\begin{array}{c}-0.110 \\
(0.022)\end{array}$ \\
\hline Ln LOED & $\begin{array}{c}0.084 \\
(0.044)\end{array}$ & $\begin{array}{c}0.013 \\
(0.028)\end{array}$ & $\begin{array}{l}-0.009 \\
(0.057)\end{array}$ & $\begin{array}{c}0.064 \\
(0.076)\end{array}$ & $\begin{array}{c}0.043 \\
(0.053)\end{array}$ \\
\hline Ln REALINC & $\begin{array}{l}-0.147 \\
(0.092)\end{array}$ & $\begin{array}{c}0.083 \\
(0.059)\end{array}$ & $\begin{array}{l}-0.126 \\
(0.118)\end{array}$ & $\begin{array}{c}0.170 \\
(0.157)\end{array}$ & $\begin{array}{c}0.304 \\
(0.109)\end{array}$ \\
\hline Ln MORT & $\begin{array}{c}1.100 \\
(0.104)\end{array}$ & $\begin{array}{c}0.466 \\
(0.067)\end{array}$ & $\begin{array}{c}0.190 \\
(0.133)\end{array}$ & $\begin{array}{c}-0.116 \\
(0.178)\end{array}$ & $\begin{array}{c}0.106 \\
(0.123)\end{array}$ \\
\hline Intercept & $\begin{array}{c}4.272 \\
(0.945)\end{array}$ & $\begin{array}{c}4.250 \\
(0.605)\end{array}$ & $\begin{array}{c}6.560 \\
(1.212)\end{array}$ & $\begin{array}{c}4.239 \\
(1.618)\end{array}$ & $\begin{array}{c}3.046 \\
(1.122)\end{array}$ \\
\hline
\end{tabular}


Table 9. Mortality Regression Results, N=313 All Areas

(1)

$$
\mathbf{R}^{2}
$$

Upper South

Deep South

Florida

West South

Big Sky

West

250-500

100-250

$<\mathbf{1 0 0}$

Not MSA

Ln LOED

Ln REALINC

Ln CIGS

Ln OBESE

Ln BLACK

Intercept
0.485

0.041

$(0.017)$

0.064

(0.012)

$-0.134$

(0.014)

0.019

(0.013)

$-0.079$

(0.012)

$-0.085$

(0.010)

$-0.013$

(0.013)

$-0.004$

(0.014)

$-0.009$

(0.011)

$-0.016$

(0.009)
(2)

0.521

(3)

0.627

0.045

(0.016)

0.025

(0.013)

$-0.096$

(0.015)

0.020

(0.013)

$-0.026$

(0.012)

$-0.009$

(0.012)

0.001

(0.012)

0.009

(0.013)

$-0.004$

(0.011)

$-0.010$

(0.011)

$\begin{array}{cc}0.076 & 0.036 \\ (0.018) & (0.023) \\ -0.141 & -0.121 \\ (0.042) & (0.049)\end{array}$

0.098

0.133

(0.027)

(0.031)

0.148

0.111

(0.024)

0.027

$(0.025)$

0.021

(0.003)

(0.004)

3.671

4.992

4.507

(0.006)

(0.428)

(0.510) 


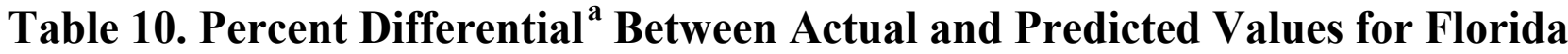 MSAs $>100,000$}

TOTUTIL

Degrees

north

latitude

$30.26 \quad$ Pensacola $\quad 3724 \quad 319$

$30.2 \quad$ Jacksonville

$29.4 \quad$ Gainesville

29.11 Daytona Beach

$29.1 \quad$ Ocala

28.33 Orlando

$28.04 \quad$ Melbourne

28.02 Lakeland

$27.58 \quad$ Tampa

27.29 Bradenton

$27.28 \quad$ Fort Pierce

27.2

26.42 West Palm Beach

26.39 Fort Meyers

$25.45 \quad$ Miami
Actual Pred. Actual Pred. TOTUTIL MORT

$4084 \quad 3310$

$3548 \quad 3190$

$3342 \quad 2524$

$3331 \quad 2610$

$4074 \quad 3120$

$3858 \quad 2843$

$3129 \quad 2814$

$3874 \quad 2992$

$3442 \quad 2800$

$3661 \quad 2690$

$3667 \quad 2478$

$4030 \quad 2607$

$3769 \quad 2435$

$4130 \quad 2820$
MORT

Percent Differential

$41.1 \quad 37.9$

16.5

8.4

$40.5 \quad 37.8$

23.4

7.0

$42.7 \quad 36.7$

$11.2 \quad 16.4$

$30.7 \quad 37.4$

$32.4 \quad-17.9$

$33.1 \quad 38.8$

27.6

$-14.7$

$37.8 \quad 37.7$

30.6

0.3

$35.8 \quad 36.9$

35.7

$-2.8$

$35.0 \quad 38.5$

$11.2-8.9$

$35.7 \quad 37.5$

$29.5 \quad-4.7$

$36.3 \quad 36.7$

$23.0-1.1$

$33.3 \quad 37.1$

$36.1 \quad-10.4$

$30.1 \quad 35.3$

$48.0 \quad-14.6$

$30.2 \quad 35.7$

54.6

$-15.4$

$29.3 \quad 36.9$

$54.8 \quad-20.5$

$33.0 \quad 37.7$

46.5

$-12.5$

a) Calculated by running regressions across 209 MSAs $>100,000$ (Florida excluded), then predicting utilization and mortality for each Florida MSA using the regression equations and the MSA values, then calculating the percentage differential between observed and predicted. 


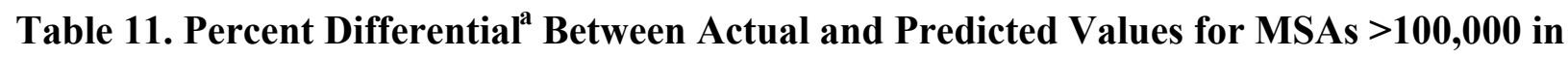
Selected States

TOTUTIL MORT

$\begin{array}{lcc}\text { ARIZONA } & & \\ \text { Phoenix } & 17.8 & -3.6 \\ \text { Tucson } & 5.7 & 6.0 \\ \text { Yuma } & 4.7 & 1.2\end{array}$

\section{MINNESOTA}

Duluth

$-5.8$

10.9

Minneapolis

$-5.5$

$-0.7$

Rochester

19.5

$-4.1$

\section{NEVADA}

Las Vegas

$-5.0$

6.5

Reno

$-5.4$

0.2

\section{OREGON}

Eugene-Springfield

Medford

Portland-Vancouver

Salem
$-6.8$

$-7.1$

$-9.7$

$-13.6$

$-12.6$

$-12.8$

$-24.6$
7.2

10.5

a) Calculated for each state by running regressions across MSAs $>100,000$ (excluding the state in question), then predicting utilization and mortality for each MSA in that state using the regression equations and the MSA values, then calculating the percentage differential between actual and predicted. 


\section{Appendix Table B1. Coefficients of Correlation ${ }^{\mathrm{a}}$ Among Ten Measures of Utilization}

\section{Part A N=313 All Areas}

TOTUTIL INUTIL OUTUTIL TOTADM MEDADM SURGADM TOTPHYS EANDM DIAG TREAT

$\begin{array}{lccccccccrrr}\text { TOTUTIL } & 1.000 & 0.748 & 0.842 & 0.562 & 0.420 & 0.651 & 0.836 & 0.728 & 0.738 & 0.778 \\ \text { INUTIL } & 0.748 & 1.000 & 0.272 & 0.947 & 0.856 & 0.780 & 0.338 & 0.352 & 0.222 & 0.314 \\ \text { OUTUTIL } & 0.842 & 0.272 & 1.000 & 0.046 & -0.086 & 0.310 & 0.938 & 0.770 & 0.890 & 0.873 \\ \text { TOTADM } & 0.562 & 0.947 & 0.046 & 1.000 & 0.947 & 0.730 & 0.058 & 0.103 & -0.014 & 0.051 \\ \text { MEDADM } & 0.420 & 0.856 & -0.086 & 0.947 & 1.000 & 0.472 & -0.087 & 0.027 & -0.134 & -0.122 \\ \text { SURGADM } & 0.651 & 0.780 & 0.310 & 0.730 & 0.472 & 1.000 & 0.346 & 0.227 & 0.250 & 0.400 \\ \text { TOTPHYS } & 0.836 & 0.338 & 0.938 & 0.058 & -0.087 & 0.346 & 1.000 & 0.873 & 0.910 & 0.915 \\ \text { EANDM } & 0.728 & 0.352 & 0.770 & 0.103 & 0.027 & 0.227 & 0.873 & 1.000 & 0.807 & 0.630 \\ \text { DIAG } & 0.738 & 0.222 & 0.890 & -0.014 & -0.134 & 0.250 & 0.910 & 0.807 & 1.000 & 0.736 \\ \text { TREAT } & 0.778 & 0.314 & 0.873 & 0.051 & -0.122 & 0.400 & 0.915 & 0.630 & 0.736 & 1.000\end{array}$

a) Weighted by population whites ages $65-84$ 


\section{Appendix Table B1. Coefficients of Correlation ${ }^{\mathrm{a}}$ Among Ten Measures of Utilization}

\section{Part B N=224 MSAs $>$ 100,000}

TOTUTIL INUTIL OUTUTIL TOTADM MEDADM SURGADM TOTPHYS EANDM DIAG TREAT

$\begin{array}{lcccccccccrr}\text { TOTUTIL } & 1.000 & 0.751 & 0.847 & 0.588 & 0.484 & 0.623 & 0.861 & 0.727 & 0.724 & 0.813 \\ \text { INUTIL } & 0.751 & 1.000 & 0.285 & 0.954 & 0.888 & 0.828 & 0.391 & 0.411 & 0.213 & 0.373 \\ \text { OUTUTIL } & 0.847 & 0.285 & 1.000 & 0.086 & -0.011 & 0.238 & 0.935 & 0.725 & 0.879 & 0.880 \\ \text { TOTADM } & 0.588 & 0.954 & 0.086 & 1.000 & 0.950 & 0.833 & 0.141 & 0.192 & 0.006 & 0.141 \\ \text { MEDADM } & 0.484 & 0.888 & -0.011 & 0.950 & 1.000 & 0.619 & 0.051 & 0.193 & -0.056 & -0.002 \\ \text { SURGADM } & 0.623 & 0.828 & 0.238 & 0.833 & 0.619 & 1.000 & 0.267 & 0.143 & 0.117 & 0.359 \\ \text { TOTPHYS } & 0.861 & 0.391 & 0.935 & 0.141 & 0.051 & 0.267 & 1.000 & 0.857 & 0.892 & 0.911 \\ \text { EANDM } & 0.727 & 0.411 & 0.725 & 0.192 & 0.193 & 0.143 & 0.857 & 1.000 & 0.776 & 0.601 \\ \text { DIAG } & 0.724 & 0.213 & 0.879 & 0.006 & -0.056 & 0.117 & 0.892 & 0.776 & 1.000 & 0.706 \\ \text { TREAT } & 0.813 & 0.373 & 0.880 & 0.141 & -0.002 & 0.359 & 0.911 & 0.601 & 0.706 & 1.000\end{array}$

a) Weighted by population whites ages $65-84$ 


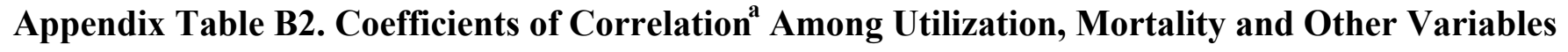

\section{$\underline{\text { Part A } \quad \mathrm{N}=313 \quad \text { All Areas }}$}

$\begin{array}{lccccccc} & \text { TOT UTIL } & \text { MORT } & \text { LOED } & \text { REAL INC } & \text { OBESE } & \text { BLACK } & \text { CIGS } \\ \text { TOTUTIL } & 1.000 & 0.119 & -0.145 & 0.191 & -0.158 & 0.383 & 0.055 \\ \text { MORT } & 0.119 & 1.000 & 0.490 & -0.275 & 0.411 & 0.398 & 0.443 \\ \text { LOED } & -0.145 & 0.490 & 1.000 & -0.610 & 0.366 & 0.067 & 0.379 \\ \text { REALINC } & 0.191 & -0.275 & -0.610 & 1.000 & -0.193 & 0.287 & -0.136 \\ \text { OBESE } & -0.158 & 0.411 & 0.366 & -0.193 & 1.000 & -0.081 & 0.209 \\ \text { BLACK } & 0.383 & 0.398 & 0.067 & 0.288 & -0.081 & 1.000 & 0.262 \\ \text { CIGS } & 0.055 & 0.443 & 0.379 & -0.136 & 0.209 & 0.262 & 1.000\end{array}$

a) Weighted by population whites ages $65-84$ 
Appendix Table B2. Coefficients of Correlation Among Utilization, Mortality and Other Variables

$\underline{\text { Part } B \quad N=224}$

$\begin{array}{lcccccccc} & \text { TOT UTIL } & \text { MORT } & \text { LOED } & \text { REAL INC } & \text { OBESE } & \text { BLACK } & \text { CIGS } & \text { POLUTN } \\ \text { TOTUTIL } & 1.000 & 0.001 & -0.170 & 0.143 & -0.153 & 0.244 & 0.096 & 0.302 \\ \text { MORT } & 0.001 & 1.000 & 0.526 & -0.216 & 0.531 & 0.395 & 0.403 & 0.086 \\ \text { LOED } & -0.170 & 0.526 & 1.000 & -0.547 & 0.474 & 0.127 & 0.336 & -0.012 \\ \text { REALINC } & 0.143 & -0.216 & -0.547 & 1.000 & -0.149 & 0.287 & 0.048 & -0.214 \\ \text { OBESE } & -0.153 & 0.531 & 0.474 & -0.149 & 1.000 & 0.085 & 0.311 & -0.040 \\ \text { BLACK } & 0.244 & 0.395 & 0.127 & 0.287 & 0.085 & 1.000 & 0.391 & -0.047 \\ \text { CIGS } & 0.096 & 0.403 & 0.336 & 0.048 & 0.311 & 0.391 & 1.000 & -0.273 \\ \text { POLUTN } & 0.302 & 0.086 & -0.012 & -0.214 & -0.040 & -0.047 & -0.273 & 1.000\end{array}$

a) Weighted by population whites ages $65-84$ 


\section{Appendix Table B3. Utilization Regression Results, OLS, $\mathrm{N}=224$ MSAs $>$ 100,000}

LnTOTUTIL

0.309

$\mathbf{R}^{2}$

Upper South

0.037

$(0.036)$

Deep South

0.053

$(0.027)$

Florida

0.197

(0.024)

West South

0.063

(0.026)

Big Sky

$-0.020$

(0.028)

West

250-500

100-250

Ln LOED

Ln REALINC

Ln MORT

Intercept
0.056

(0.017)

$-0.062$

(0.021)

$-0.087$

(0.022)
0.043

(0.047)

(0.094)

(0.114)

0.418

0.343

0.581

Ln INUTIL

Ln OUTUTIL

0.021

0.003

0.058

(0.037)

(0.034)

(0.055)

0.011

0.006

0.022

(0.027)

(0.025)

(0.040)

0.289

0.121

0.533

(0.028)

(0.026)

(0.041)

0.043

(0.028)

0.063

0.010

(0.026)

(0.042)

0.012

0.090

$-0.146$

(0.027)

$(0.025)$

(0.040)

0.115

0.108

0.130

(0.021)

(0.019)

(0.031)

$-0.055$

$-0.049$

$-0.062$

$(0.019)$

(0.018)

(0.029)

$-0.083$

$-0.066$

$-0.116$

(0.021)

(0.019)

(0.031)

$\begin{array}{ll}-0.090 & 0.025\end{array}$

$-0.004$

0.073

$(0.048)$

(0.044)

(0.072)

$0.093 \quad 0.066$

$-0.035$

0.232

$(0.102)$

(0.095)

(0.153)

$$
0.186 \quad 0.627
$$

0.799

0.343

(0.106)

(0.099)

(0.159)

$\begin{array}{ccc}8.083 & 6.441 & 5.172 \\ (0.010) & (0.921) & (1.019)\end{array}$

5.053

3.624

(0.948)

(1.526) 


\section{Appendix Table B4. Utilization Regression Results by Type of Service, OLS, N=224 \\ MSAs $>100,000$}

\section{Ln MEDADM Ln SURGADM LnEANDM LnDIAG LnTREAT}

$$
\mathbf{R}^{2}
$$

0.452

0.289

0.410

0.443

0.615

Upper South

$$
-0.017
$$

$-0.041$

0.040

0.034

0.137

(0.044)

(0.029)

(0.061)

(0.079)

(0.052)

Deep South

$$
0.006
$$

0.003

$-0.091$

$-0.037$

0.057

(0.032)

(0.021)

(0.044)

(0.058)

(0.038)

Florida

$$
0.046
$$

0.091

0.274

0.511

0.527

(0.033)

(0.022)

(0.045)

(0.059)

(0.039)

West South

$$
0.056
$$

0.050

$-0.036$

0.022

0.132

(0.033)

(0.022)

(0.046)

(0.060)

(0.039)

Big Sky

$$
0.129
$$

(0.032)

0.060

(0.021)

West

250-500

100-250

Ln LOED

0.085

(0.024)

0.084

(0.016)

$-0.130$

(0.044)

$-0.170$

(0.058)

0.060

(0.038)

$-0.011$

(0.015)

$-0.033$

(0.016)

(0.025)

$-0.001$

(0.056)

$-0.002$

(0.038)

0.109

(0.080)

0.613

(0.084)

3.447

(0.803)
0.107

(0.034)

$-0.154$

(0.032)

$-0.205$

(0.034)

0.012

(0.078)

$-0.105$

(0.167)

0.174

(0.174)

0.089

(0.044)

$-0.131$

(0.041)

$-0.171$

(0.045)

0.078

(0.102)

0.293

(0.217)

0.081

(0.226)

6.436

(1.672)
2.371

(2.173)
0.284

(0.029)

$-0.038$

(0.027)

$-0.085$

(0.029)

0.072

(0.067)

0.244

(0.142)

0.330

(0.148)

2.815

(1.422) 
Appendix Table B5. Utilization Regression Results, Two-Stage Least Squares (standard error in parenthesis)

Part A N=313 All Areas

Ln TOTUTIL Ln INUTIL Ln OUTUTIL

$\mathbf{R}^{2}$

0.422

0.246

0.637

Upper South

0.018

0.022

0.009

(0.027)

(0.025)

(0.040)

Deep South

0.028

0.027

0.032

(0.021)

(0.020)

(0.031)

Florida

0.295

0.114

0.557

(0.029)

(0.027)

(0.043)

West South

0.045

0.063

0.011

(0.020)

(0.019)

(0.031)

Big Sky

0.030
$(0.022)$

0.092

$-0.109$

(0.022)

(0.021)

(0.033)

West

0.105

0.094

0.122

(0.020)

(0.019)

(0.030)

250-500

$$
-0.054
$$

$-0.053$

$-0.054$

(0.019)

(0.018)

(0.029)

100-250

$-0.087$

$-0.074$

$-0.111$

(0.020)

(0.019)

(0.030)

$<100$

$-0.053$

$-0.027$

$-0.100$

(0.017)

(0.016)

(0.025)

Not MSA

$$
-0.070
$$

$-0.041$

$-0.128$

(0.017)

(0.016)

(0.025)

Ln LOED

0.015

0.042

$-0.031$

(0.039)

(0.037)

(0.058)

Ln REALINC

$$
\begin{gathered}
0.034 \\
(0.075)
\end{gathered}
$$

$-0.032$

0.166

(0.071)

(0.112)

Pred. Ln MORT

$$
\begin{gathered}
0.758 \\
(0.185)
\end{gathered}
$$

0.703

0.811

(0.174)

(0.276)

Intercept

5.000

5.424

2.438

(1.020)

(0.961)

(1.525)

Note: First stage used to predict regressions can be found in Table 9 
Appendix Table B5. Utilization Regression Results, Two-Stage Least Squares (standard error in parenthesis)

Part B N=224 MSAs $>100,000$

Ln TOTUTIL Ln INUTIL Ln OUTUTIL

$\mathbf{R}^{2}$

0.381

0.260

0.528

Upper South

0.000

$-0.007$

0.017

$(0.041)$

(0.036)

(0.065)

Deep South

$$
-0.022
$$

$-0.009$

$-0.043$

(0.031)

(0.027)

(0.049)

Florida

$$
0.369
$$

0.156

0.687

(0.038)

(0.033)

(0.060)

West South

0.031

0.058

$-0.013$

(0.031)

(0.027)

(0.049)

Big Sky

0.036
$(0.030)$

0.100

$-0.098$

(0.030)

(0.026)

(0.048)

West

$$
0.153
$$

(0.025)

0.124

0.204

(0.022)

(0.040)

250-500

$-0.042$

(0.022)

$-0.043$

$-0.038$

(0.019)

(0.034)

100-250

$$
-0.072
$$

$-0.061$

$-0.095$

(0.023)

(0.020)

(0.037)

Ln LOED

$-0.048$

$-0.036$

$-0.067$

(0.056)

(0.049)

(0.089)

Ln REALINC

$$
0.063
$$

$-0.037$

0.225

$(0.112)$

$(0.097)$

$(0.177)$

Pred. Ln MORT

$$
1.332
$$

1.106

1.702

$(0.229)$

$(0.198)$

(0.362)

Intercept

$$
\begin{gathered}
2.549 \\
(1.339)
\end{gathered}
$$$$
3.907
$$$$
-1.438
$$$$
\text { (1.160) }
$$

Note: First stage used to predict regressions can be found in Table 9 
Appendix Table B5. Utilization Regression Results, Two-Stage Least Squares (standard error in parenthesis)

Part A N=313 All Areas, cont.

\section{Ln MEDADM Ln SURGADM}

$\mathbf{R}^{2}$

Upper South

Deep South

Florida

West South

Big Sky

West

250-500

100-250

$<100$

Not MSA

Ln LOED

Ln REALINC

Pred. Ln MOR

(0.225)

Intercept

$\begin{array}{cc}-0.147 & 0.090 \\ (0.092) & (0.060)\end{array}$

1.123

$$
0.023
$$

(0.033)

$$
0.044
$$

(0.025)

$$
0.060
$$

(0.035)

$\begin{array}{cc}0.063 & 0.048 \\ (0.025) & (0.016)\end{array}$

0.141

(0.027)

0.082

(0.024)

$$
-0.067
$$

(0.024)

$$
-0.086
$$

(0.025)

0.008

(0.021)

$$
\begin{gathered}
0.010 \\
(0.021)
\end{gathered}
$$

0.082
$(0.047)$

$$
4.181
$$

(1.246)

0.684

(0.147)

3.366

(0.812)
Ln EANDM
0.544

0.019

(0.043)

$-0.047$

(0.033)

0.301

(0.046)

$-0.036$

(0.032)

$-0.091$

(0.035)

0.099

(0.031)

$-0.150$

(0.031)

$-0.208$

(0.032)

$-0.186$

(0.027)

$-0.220$

(0.027)

$-0.039$

(0.062)

$-0.115$

(0.119)

Ln DIAG

0.564

0.001

(0.057)

0.007

(0.044)

0.551

(0.061)

0.071

(0.043)

$-0.105$

(0.047)

0.092

(0.042)

$-0.131$

(0.041)

$-0.178$

(0.043)

$-0.240$

(0.036)

$-0.260$

(0.036)

0.021

(0.082)

0.187

(0.159)

0.553

(0.293)

5.087

(1.617)
0.392

(0.391)

2.176

(2.162)

\section{Ln TREAT}

0.608

0.080

(0.039)

0.069

(0.030)

0.455

(0.042)

0.114

(0.030)

0.036

(0.032)

0.236

(0.029)

$-0.040$

(0.028)

$-0.084$

(0.030)

$-0.063$

(0.025)

$-0.114$

(0.024)

0.051

(0.056)

0.301

(0.109)

0.011

(0.268)

3.432

(1.481)

Note: First stage used to predict regressions can be found in Appendix Table B6 
Appendix Table B5. Utilization Regression Results, Two-Stage Least Squares (standard error in parenthesis)

Part B N=224 MSAs > 100,000, cont.

\begin{tabular}{|c|c|c|c|c|c|}
\hline & Ln MEDADM & Ln SURGADM & Ln EANDM & Ln DIAG & Ln TREAT \\
\hline $\mathbf{R}^{2}$ & 0.358 & 0.229 & 0.394 & 0.419 & 0.587 \\
\hline Upper South & $\begin{array}{c}-0.024 \\
(0.044)\end{array}$ & $\begin{array}{c}-0.053 \\
(0.031)\end{array}$ & $\begin{array}{c}0.012 \\
(0.065)\end{array}$ & $\begin{array}{l}-0.008 \\
(0.086)\end{array}$ & $\begin{array}{c}0.111 \\
(0.056)\end{array}$ \\
\hline Deep South & $\begin{array}{l}-0.004 \\
(0.034)\end{array}$ & $\begin{array}{l}-0.015 \\
(0.023)\end{array}$ & $\begin{array}{l}-0.136 \\
(0.050)\end{array}$ & $\begin{array}{c}-0.102 \\
(0.065)\end{array}$ & $\begin{array}{c}0.016 \\
(0.043)\end{array}$ \\
\hline Florida & $\begin{array}{c}0.071 \\
(0.041)\end{array}$ & $\begin{array}{c}0.133 \\
(0.028)\end{array}$ & $\begin{array}{c}0.380 \\
(0.060)\end{array}$ & $\begin{array}{c}0.666 \\
(0.079)\end{array}$ & $\begin{array}{c}0.626 \\
(0.052)\end{array}$ \\
\hline West South & $\begin{array}{c}0.052 \\
(0.033)\end{array}$ & $\begin{array}{c}0.044 \\
(0.023)\end{array}$ & $\begin{array}{l}-0.052 \\
(0.049)\end{array}$ & $\begin{array}{c}-0.002 \\
(0.065)\end{array}$ & $\begin{array}{c}0.117 \\
(0.042)\end{array}$ \\
\hline Big Sky & $\begin{array}{c}0.137 \\
(0.033)\end{array}$ & $\begin{array}{c}0.073 \\
(0.023)\end{array}$ & $\begin{array}{l}-0.097 \\
(0.048)\end{array}$ & $\begin{array}{l}-0.121 \\
(0.064)\end{array}$ & $\begin{array}{c}0.090 \\
(0.042)\end{array}$ \\
\hline West & $\begin{array}{c}0.098 \\
(0.027)\end{array}$ & $\begin{array}{c}0.105 \\
(0.019)\end{array}$ & $\begin{array}{c}0.158 \\
(0.040)\end{array}$ & $\begin{array}{c}0.164 \\
(0.053)\end{array}$ & $\begin{array}{c}0.331 \\
(0.034)\end{array}$ \\
\hline $250-500$ & $\begin{array}{l}-0.056 \\
(0.023)\end{array}$ & $\begin{array}{l}-0.004 \\
(0.016)\end{array}$ & $\begin{array}{l}-0.137 \\
(0.035)\end{array}$ & $\begin{array}{l}-0.107 \\
(0.046)\end{array}$ & $\begin{array}{c}-0.023 \\
(0.030)\end{array}$ \\
\hline $100-250$ & $\begin{array}{l}-0.069 \\
(0.025)\end{array}$ & $\begin{array}{l}-0.027 \\
(0.017)\end{array}$ & $\begin{array}{c}-0.191 \\
(0.037)\end{array}$ & $\begin{array}{l}-0.150 \\
(0.049)\end{array}$ & $\begin{array}{l}-0.072 \\
(0.032)\end{array}$ \\
\hline Ln LOED & $\begin{array}{c}-0.024 \\
(0.061)\end{array}$ & $\begin{array}{l}-0.041 \\
(0.042)\end{array}$ & $\begin{array}{l}-0.085 \\
(0.090)\end{array}$ & $\begin{array}{c}-0.064 \\
(0.118)\end{array}$ & $\begin{array}{c}-0.018 \\
(0.077)\end{array}$ \\
\hline Ln REALINC & $\begin{array}{c}-0.145 \\
(0.121)\end{array}$ & $\begin{array}{c}0.107 \\
(0.084)\end{array}$ & $\begin{array}{l}-0.110 \\
(0.178)\end{array}$ & $\begin{array}{c}0.285 \\
(0.235)\end{array}$ & $\begin{array}{c}0.240 \\
(0.153)\end{array}$ \\
\hline Pred. Ln MOR' & $\begin{array}{c}1.385 \\
(0.247)\end{array}$ & $\begin{array}{c}0.989 \\
(0.172)\end{array}$ & $\begin{array}{c}1.113 \\
(0.365)\end{array}$ & $\begin{array}{c}1.456 \\
(0.481)\end{array}$ & $\begin{array}{c}1.199 \\
(0.313)\end{array}$ \\
\hline Intercept & $\begin{array}{c}3.096 \\
(1.445)\end{array}$ & $\begin{array}{c}2.044 \\
(1.005)\end{array}$ & $\begin{array}{c}2.941 \\
(2.132)\end{array}$ & $\begin{array}{l}-2.750 \\
(2.815)\end{array}$ & $\begin{array}{c}-0.423 \\
(1.833)\end{array}$ \\
\hline
\end{tabular}

Note: First stage used to predict regressions can be found in Appendix Table B6 
(1)

$$
\mathbf{R}^{2}
$$

Upper South

0.011

$(0.022)$

Deep South

0.056

(0.017)

Florida

West South

Big Sky

West

250-500

100-250

Ln LOED

Ln REALINC

Ln CIGS

Ln OBESE

Ln POLUTN

Ln BLACK

Intercept
$-0.012$

(0.013)

$-0.006$

(0.014)
3.672
(2)

0.517

(3)

0.645

0.055

(0.023)

0.043

(0.018)

$-0.088$

(0.017)

0.051

(0.016)

0.004

(0.016)

$-0.008$

(0.016)

0.008

(0.012)

0.016

(0.013)

$$
\text { (0.013) }
$$

$\begin{array}{cc}0.115 & 0.021 \\ (0.025) & (0.029) \\ -0.031 & -0.178 \\ (0.055) & (0.064)\end{array}$

$0.088 \quad 0.142$

$(0.039) \quad(0.044)$

$0.169 \quad 0.138$

$(0.032) \quad(0.036)$

$0.057 \quad 0.045$

$(0.021) \quad(0.024)$

$0.024 \quad 0.026$

(0.005) (0.006)

3.879

4.900

(0.006)

(0.578)

(0.692) 